\title{
EL EJERCICIO DE LAS OBJECIONES DE CONCIENCIA EN UNA SOCIEDAD POSTMODERNA*
}

\author{
ALEJANDRO GONZÁLEZ-VARAS IBÁŃEZ
}

RESUMEN: La heterogeneidad religiosa y de valores que presentan las sociedades postmodernas propicia que surjan conflictos entre el contenido de las normas jurídicas y la conciencia de los destinatarios. Los objetores invocan el derecho fundamental de libertad religiosa para fundamentar sus pretensiones. Se parte del ordenamiento jurídico espańol y de otros de su entorno para examinar el contenido y límites del derecho a la objeción de conciencia y las posibilidades de regular su ejercicio. El autor también examina los mecanismos que existen para ponderar el interés particular del objetor y el interés general representado por la norma. Dedica también atención a la posibilidad de que aumenten las objeciones de conciencia en los casos en que el legislador no adapta el contenido de la norma a las necesidades sociales, sino que emplea la norma para transmitir unos contenidos que no son generalmente compartidos. El resultado puede ser la transformación de la mentalidad social y el aumento de casos de objeción de conciencia.

PALABRAS CLAVE: Postmodernidad - objeción de conciencia - libertad religiosa - potestad legislativa - ponderación de intereses en conflicto.

\section{EXERCISING THE CONSCIENTIOUS OBJECTIONS IN A POSTMODERN SOCIETY}

ABSTRACT: The religious and moral diversity that postmodern societies feature bring about conflicts between the content of legal rules and

La realización de este artículo se encuentra dentro del marco de actuación del Proyecto de Investigación Conflicto intercultural y Derecho islámico: soluciones para la integración jurídica de la diversidad en Aragón, PI055/08, financiado por la Diputación General de Aragón (EsPAÑA). El contenido de este artículo ha partido de las bases establecidas en el estudio realizado por el mismo autor titulado Derecho y conciencia en las profesiones sanitarias publicado por la editorial Dykinson, Madrid, 2009.

- $\quad$ Doctor en Derecho por las universidades de Bolonia (Italia) y Vigo (España). Profesor Ayudante, Doctor de la Universidad de Zaragoza (España). Facultad de Derecho. Correo electrónico: agvaras@unizar.es

Fecha de recepción: 1 de septiembre de 2009.

Fecha de aprobación: 10 de diciembre de 2009. 
the conscience of people that are bound to obey them. Conscientious objectors invoke the fundamental right of religious freedom to base their claims. This essay examines the Spanish legal system and others of the same context to review the content and limits of the right to conscientious objection, and the existing possibilities to regulate its exercise. The author also explains the actual setup to balance the objector's particular interest and the general interest represented by the positive norm. He also pays attention to the likelihood that conscientious objections increase in cases in which rule makers not only do not adapt the rule content to the society's needs, but also use it to transmit new concepts that are not generally shared by the society. The result can be a modification of society's mindset, and an increase of conscientious objections.

KEY WORDS: Postmodernism - Conscientious objection - Religious freedom - Legislative Powers - Balance between controversial interests.

Sumario: Introducción. 1. Noción de objeción de conciencia. 2. Los ordenamientos jurídicos en la sociedad postmoderna. 2.1. Una sociedad, un Derecho y varias éticas. 2.2. La valoración de la autonomía y dignidad humanas. 3. La actividad legislativa y el contenido ofrecido a la norma juridica. 3.1. El espacio jurídico reservado a los valores y la actitud de los poderes públicos ante ellos. 3.2. El contenido de la ley: la propuesta de la sociedad al legislador, o del legislador a la sociedad. 3.3. La Ley entre Derecho y política. 4. La relevancia de las objeciones de conciencia. 4.1. Su creciente frecuencia. 4.2. La solución a los conflictos jurídicos a través de las objeciones de conciencia. 5. Limites de la objeción de conciencia. 6. Posibilidad de regular las objeciones de conciencia. Conclusiones. Bibliografía ${ }^{1}$.

\section{INTRODUCCIÓN}

La sociedad actual, que tiene como uno de los elementos que la caracterizan la heterogeneidad de carácter cultural, ético y moral, provoca que aumente paulatinamente la dificultad de encontrar el adecuado equilibrio entre el contenido de las normas jurídicas y los criterios de actuación de los ciudadanos. Este clima social postmoderno favorece que

\footnotetext{
Abreviaturas: ADEE: Anuario de Derecho Eclesiástico del Estado; CCB: Comité Consultatif de Bioéthique (BÉlgiCA); CNB: Comitato Nazionale per la Bioetica (ItaliA); DE: Il Diritto Ecclesiastico; FJ: Fundamento jurídico; IC: Ius Canonicum; QDPE: Quaderni di Diritto e Politica Ecclesiastica; RDGH: Revista de Derecho y Genoma Humano; RGDCEE: Revista General de Derecho Canónico y Eclesiástico de Estado [Disponible en http://www. iustel.com]; STC: Sentencia del Tribunal Constitucional español; STEDH: Sentencia del Tribunal Europeo de Derechos Humanos; STS: Sentencia del Tribunal Supremo español.
} 
algunos ciudadanos se nieguen a cumplir con el contenido de las normas por ser estas contrarias a sus conciencias. Este fenómeno irá en aumento de una forma proporcional a la disgregación ética, moral y religiosa de nuestras sociedades, y se acrecentará en aquellos casos en que el legislador utilice las normas como medios de exponer unas conductas que se alejen de los parámetros mantenidos hasta ese momento. Ante esta situación, el objeto de este estudio consiste en ofrecer unas reflexiones sobre lo que actualmente se entiende por objeciones de conciencia (apartado 1). A continuación se profundiza en la relación que tienen las aludidas características de nuestra sociedad con la función del Derecho (apartados 2 y 3) y de qué modo inciden en la aparición de las objeciones de conciencia (apartado 4). Efectivamente, cuando la objeción es legítima, se producirá una tensión entre el imperativo moral de la persona, y el imperativo legal -al que está también sujeto- establecido en la norma positiva. Estas situaciones requieren las oportunas soluciones, tema que continúa siendo abordado en el apartado 4. Se finalizará exponiendo cuáles son los límites de las objeciones de conciencia (apartado 5) y las posibilidades que existen de regular su ejercicio (apartado 6). Este trabajo se desarrolla a partir del análisis del Derecho espańol y de hacer las referencias que se estiman oportunas al Derecho comparado. No obstante ello, los principios generales que se infieren son extrapolables a cualquier ordenamiento que comparta la tradición jurídica de origen europeo-continental.

\section{1) NOCIÓN DE OBJECIÓN DE CONCIENCIA}

Ofrecer una explicación generalmente compartida de lo que se entiende por objeción de conciencia no es una tarea exenta de dificultades. Sobre ello la doctrina ha desarrollado intensos debates, y ni aun los pronunciamientos de los órganos jurisdiccionales, al menos los espańoles, han conseguido establecer definitivamente unos criterios uniformes. No obstante, se puede comenzar afirmando que la objeción de conciencia, en términos generales, es susceptible de concebirse como la negativa del individuo, por motivos de conciencia, a someterse a una conducta que en, principio, sería jurídicamente exigible, ya provenga esa obligación directamente de la norma, de un contrato, de un mandato judicial o de una resolución administrativa ${ }^{2}$. Incluso, más ampliamente, podría sostenerse que la noción de objeción incluye "toda pretensión contraria a la ley motivada por razones axiológicas -no meramente psicológicas-, de contenido primordialmente religioso o ideológico, ya tenga por objeto la elección menos lesiva para la propia conciencia entre las alternativas pre-

2 Navarro Valls, R. / Martínez Torrón, J. (1997). Las objeciones de conciencia en el Derecho español y comparado. Madrid: McGraw Hill, p. 14. 
vistas en la norma, eludir el comportamiento contenido en el imperativo legal o la sanción prevista por su incumplimiento, o incluso, aceptando el mecanismo represivo, lograr la alteración de la ley que es contraria al personal imperativo ético" 3 . Atendiendo a las características que presenta, se concibe que la objeción de conciencia, cuando es legítima, constituye una manifestación de la libertad de conciencia, derecho fundamental reconocido en el artículo 16 de la Constitución española y que puede ejercerse aun cuando no haya habido regulación expresa del legislador ${ }^{4}$.

Tal como se ha expuesto, esa conducta obligada puede derivar de un imperativo normativo, de un contrato, de mandato judicial o de resolución administrativa; en definitiva, pueden objetarse tanto deberes de Derecho público como de Derecho privado. En este último caso, lo que vulnera la conciencia del objetor consiste en un deber que proviene de un sujeto particular respaldado expresa o tácitamente por una norma de Derecho privado que le habilita y que, atendiendo a su carácter plenamente jurídico, se encuentra garantizada por el aparato coercitivo del Estado 5 . Ante estas situaciones, el objetor se ve sometido a un conflicto interior: el deber externo de cumplir esa conducta, y la voz interior que le impulsa a comportarse de un modo contrario ${ }^{6}$. Expresado en otros términos ${ }^{7}$, puede afirmarse que consiste en una relación dialéctica entre la ley positiva de

Navarro Valls, R. / Martínez Torrón, J. (1997) 14 y ss.

4 Véanse las sentencias del Tribunal Constitucional español 15/1982, principalmente FFJJ sexto y octavo, y 53/1985, FJ decimocuarto. Es preciso indicar que la doctrina del Tribunal Constitucional español sobre esta cuestión no ha sido uniforme. Encontramos que las sentencias 160 y 167 de 1987 (principalmente, FJ tercero de cada una de ellas), referidas a la objeción de conciencia al servicio militar, sostienen que no puede ejercitarse la objeción de conciencia si no es por medio de una norma que así lo reconozca expresamente. Este planteamiento es consecuencia de la desvinculación que realiza el Tribunal, en esas mismas sentencias, entre la objeción de conciencia y el artículo 16 de la Constitución espańola.

Escobar Roca, G. (1993). La objeción de conciencia en la Constitución española. Madrid: Centro de Estudios Constitucionales, p. 45. Parte de la doctrina entiende que el elemento común a las objeciones de conciencia provenientes tanto de los mandatos de Derecho público como de Derecho privado estriba en que el ordenamiento jurídico no ofrece una respuesta concluyente $y$, como regla general, no suele existir un reconocimiento expreso de la posibilidad de objetar. Frente a ello, una de las diferencias principales que median entre ambos orígenes consiste en que, en el ámbito de las relaciones jurídicas privadas, concurre un principio suplementario de la objeción como es el respeto a la autonomía de la voluntad y a los compromisos pactados. Se trata de una cuestión, por lo demás, de amplio alcance desde el momento en que afecta al debate jurídico que surge en torno a la eficacia de los derechos fundamentales entre particulares, como indica Prieto Sanchís, L. (2007). "Desobediencia civil y objeción de conciencia”. En AA.VV.: Objeción de conciencia y función pública. Estudios de Derecho Judicial, No 89, Madrid: Consejo General del Poder Judicial, p. 22. Martínez Torrón, J. (2005). "Las objeciones de conciencia de los católicos". RGDCEE, No 9, septiembre, p. 3.; Palomino, R. (1994). Las objeciones de conciencia. Madrid: Montecorvo, pp. 19-22.

Bertolino, R. (1994). L'obiezione di coscienza "moderna". Per una fondazione costituzionale del diritto di obiezione. Torino: Giappichelli, pp. 18 y ss.; Lo Castro, G (1989). "Legge e coscienza". QDPE, № 2, p. 17. 
carácter heterónomo, y la ley moral o autónoma del individuo que desembocan en un conflicto entre la conducta "legal" y la "legítima" que es resultado de una elección personal de valores.

El conflicto entre conciencia y norma jurídica tiene su origen en que la conciencia es un juicio, un acto de la inteligencia por el que se pondera un hecho, conducta o suceso, aprobándolo o desaprobándolo, dictaminando sobre su bondad o malicia. Sin embargo, no hemos de confundir la conciencia con la ley moral. Aquella está subordinada a esta. La conciencia examina actos y comportamientos, y los coteja con esta ley. El juicio o crítica que la conciencia realiza sobre esos actos, su aprobación o censura, dependerá de que se ajusten en mayor o menor grado a la ley moral. Por tanto, la conciencia no crea normas, sino que las aplica a las conductas o hechos ${ }^{8}$.

Si se ha indicado qué se entiende por conciencia ${ }^{9}$, se debe señalar que esta no puede existir sin ciencia, es decir, sin conocimiento. La conciencia analiza el grado de adecuación de la conducta o los hechos con la ley, pero sin la ciencia o conocimiento de la ley, la conciencia no tendría sentido, se equivocaría y juzgaría erróneamente ${ }^{10}$.

Al mismo tiempo, la ciencia necesita a la conciencia desde el momento en que esta implica un cierto ordenamiento de la razón. Por ello, la ciencia positiva necesita a la conciencia para que la guíe adecuadamente. Aquella no puede, por tanto, ir contra la conciencia del hombre porque acabaría negándolo. El resultado ${ }^{11}$ es que la ciencia positiva que se aplica a la persona ha de estar garantizada por la conciencia ética.

8 Polaino-Lorente, A. (1994). "Ciencia y conciencia". En él mismo (Dir.): Manual de Bioética general. Madrid: Rialp, p. 38. Se adentra más en el conflicto entre la conciencia y la legalidad en el capítulo escrito por el mismo autor en el mismo libro titulado "Más allá de la confusión: razones para la prioridad de la bioética", particularmente en las pp. 92 y ss.

9 Cabe ańadir la indicación de alguna acepción genérica clarificadora. De este modo, el Diccionario de la Real Academia de la Lengua Española (22a ed., 2001) indica tres significados principales: a) Propiedad del espíritu humano de reconocerse en sus atributos esenciales y en todas las modificaciones que en sí mismo experimenta; b) Conocimiento interior del bien y del mal; c) Conocimiento reflexivo de las cosas; d) Actividad mental a la que solo puede tener acceso el propio sujeto; e) Acto psíquico por el que un sujeto se percibe a sí mismo en el mundo. Define también la conciencia errónea como la que con ignorancia juzga lo verdadero por falso, o lo falso por verdadero, teniendo lo bueno por malo o lo malo por bueno. Desde un punto de vista filosófico, "hay que constatar la ambigüedad esencial que afecta a este término, ya que la riqueza semántica que posee en el lenguaje ordinario cubre solo en parte su significación técnica. Dos sentidos principales se han dado a la palabra: 1) Capacidad que tiene el hombre no solo de conocer objetos, ya sean externos (cosas) o internos a él (estados interiores), sino de advertir que conoce. 2) Facultad de conocer el valor moral de los estados interiores y de los actos que el hombre pone como propios", según Lois Cabello, M. C. (1987). "conciencia", en AA.VV.: Gran Enciclopedia, Madrid: Rialp, tomo VI, p. 174.

10 Polaino-Lorente, A. (1994) 38.

11 Polaino-Lorente, A. (1994) 38 y ss. 


\section{2) LOS ORDENAMIENTOS JURÍDICOS EN LA SOCIEDAD POSTMODERNA}

\section{(2.1) UNA SOCIEDAD, UN DERECHO Y VARIAS ÉTICAS}

Una vez analizado el significado de las objeciones de conciencia es momento de adentrarnos en el alcance y proyecciones que ofrecen en el contexto social y jurídico actual. Conviene tener en cuenta que la actividad normativa se desarrolla dentro de un clima de dispersión y heterogeneidad ética donde aparecen criterios distintos para enjuiciar la realidad. A medida que en la sociedad continúan surgiendo nuevas problemáticas, cabe plantearse la oportunidad de acudir al legislador con el fin de instarle a que regule estas cuestiones. Sin embargo, no es fácil ofrecer una respuesta unívoca ante los distintos acontecimientos que afectan a la conciencia humana por la carencia de unanimidad de criterio en el momento de afrontar estas cuestiones.

No podemos desconocer que la denominada "sociedad postmoderna" se define "compleja y multiética" 12 . De aquí deriva la dificultad de encontrar un común denominador ético para la sociedad que será más inalcanzable a medida que aumenta ese pluralismo ideológico, ético y religioso. Por tanto, localizar los vínculos de conexión entre lo jurídico y lo ético se dificulta paulatinamente ${ }^{13}$. Encontrar un discurso argumentativo estrictamente jurídico se presenta como una empresa no exenta de dificul$\operatorname{tades}^{14}$.

La adecuada comprensión de este planteamiento general que afecta a la época "postmoderna" requiere que analicemos su origen, aunque sea de un modo somero. Para ello, resulta oportuno contrastarla con el planteamiento social y jurídico "moderno". Nos estamos refiriendo con ello a un concepto de ley caracterizado por su generalidad y racionalidad, por lo que no regula casos concretos, sino que vale para un número indefinido de actos y hechos. "Es una regla uniforme que reduce a común denominador, y de una vez para siempre, toda la posible pluralidad de los fenómenos vitales [...]. Al mismo tiempo que general, ha de ser precisa, ya que nada puede quedar para la decisión arbitraria" 15 .

Dalla Torre, G. (1993). Bioetica e Diritto. Saggi. Torino: Giapicchelli, pp. 14 y ss.

Ballesteros, J. (2000). "Postmodernidad y tercer milenio". Persona y Derecho, No 43, p. 16; Dalla Torre, G. (1993) 6,7, 107 y 108; Palazzani, L. (2002). "Diritto e morale di fronte alla protezione della vita umana". Persona y Derecho, No 46, pp. 169 y ss.

En relación con esta cuestión, D'Agostino, F. (1987). "Il problema della bioetica in una società pluralistica", en AA. VV.: Atti dell'8 $8^{\circ}$ Congresso della Società italiana di medicina interna. Roma: Pozi, pp. 8-15; D’Agostino, F. (1991). "Dalla bioetica alla biogiuridica". Persona y Derecho, No 24, p. 13.

García-Pelayo, M. (1999). Derecho constitucional comparado. Madrid: Alianza Editorial, p. 78 . 
Este concepto es resultado de una actitud intelectual que mostró su máximo esplendor durante el siglo XIX y que provenía, a su vez, del racionalismo que influyó decisivamente en los distintos aspectos de la actividad humana durante los siglos XVII y XVIII. Este contexto se caracterizó por la afirmación de la existencia de una ética generalmente compartida y en la existencia de una "razón general, por encima de las individualidades históricas, sociológicas y antropológicas; una naturaleza humana general, pues solo bajo este supuesto, se pensaba, puede ser conocedora, cognoscible y universalmente regulable; solo bajo este supuesto es reducible a leyes generales de cualquier contenido" 16 . En consecuencia, la ley domina todo y fuera de ella existe el caos y el desorden. No es que la ley forme parte del orden, sino que ella misma es el orden ${ }^{17}$. Efectivamente, es teniendo en cuenta los postulados de la época como se logró presentar un concepto de ley que era capaz de agotar todo el Derecho ${ }^{18}$ y de regular los distintos aspectos de la vida humana. Este carácter omnicomprensivo de la ley ha dado lugar, en último término, a una injerencia de las normas jurídicas incluso en campos habitualmente reservados a la conciencia singular del individuo ${ }^{19}$. Incluso se ha relegado la conciencia a ámbitos cada vez más personales y menos públicos ${ }^{20}$.

Estos postulados no pueden considerarse actualmente válidos desde el momento en que sus mismos presupuestos o fundamentos han cambiado. Si el concepto moderno de la ley partía de una serie de elementos universalmente compartidos, como eran una ética y unos valores, y un semejante modo de razonar, la actual "sociedad postmoderna" parte de la fragmentación ética, de valores, y de los distintos modos de desarrollarse el razonamiento humano. Esto es consecuencia del creciente proceso de "privatización ética" o del progresivo "particularizarse de lo moral" que da lugar al "politeísmo ético"21, llegando en ocasiones a un exacerbado individualismo que considera que el ser humano es un sujeto aislado que

García-Pelayo, M. (1999) 69.

García-Pelayo, M. (1999) 70. Seńala el mismo autor en este mismo lugar que este pensamiento en sí no era del todo nuevo, pues en ciertos aspectos contaba ya con una tradición escolástica; "pero sí era nueva, en cambio, la concepción y el significado nuevo de la ley. Pues en la escolástica era expresión de un entendimiento y de una voluntad divina que, en consecuencia, podía suspender su vigencia; en cambio, ahora es descubierta por la razón humana, y el mismo Dios se convierte en pura ley (deísmo)".

Lo Castro, G. (1997). Il mistero del Diritto. Torino: Giappichelli, pp. 4, 5, 13 y 15; García-Pelayo, M. (1999) 68 in fine.

Navarro-Valls, R. / Palomino, R. (1994). "Las objeciones de conciencia", en AA. VV.: Tratado de Derecho eclesiástico. Pamplona: EUNSA, p. 1090; Martínez Torrón, J. (1989). "Las objeciones de conciencia en el Derecho internacional". QDPE, № 2, p. 106 . Véase asimismo Martín Mateo, R. (1987). Bioética y Derecho. Barcelona: Ariel, pp. 10 y 69 y ss. Bettetini, A. (2003). "Sobre las relaciones entre religión, Derecho canónico y Derecho político en la sociedad posmoderna". RGDCEE, № 3, octubre, p. 9.

D’Agostino, F. (2000). "Ética y Derecho entre lo moderno y lo postmoderno". Persona y Derecho, No 42, pp. 18 y ss.; Palazzani, L. (2002) 169 y ss. 
agota en sí mismo su desarrollo y plenitud ${ }^{22}$. Se produce una situación en que el hombre se encuentra desprovisto de algunos de los elementos fundamentales que constituían su vida y valores, como son la religión, la tradición o las costumbres. Su lugar ha sido ocupado por otros entre los que prima el juicio personal y la autonomía de una conciencia individual que provoca que una de las nuevas convicciones sea el pleno dominio y modos propios de valorarla ${ }^{23}$. La consecuencia de este subjetivismo ético se traduce en que cada vez es más difícil encontrar unos valores y unas normas por todos aceptadas ${ }^{24}$.

Se considera que la modernidad ha fracasado y no puede continuar ofreciendo, en consecuencia, la ética y su jerarquía de valores y preceptos. La postmodernidad ensalza las diferencias, considerando que lo único claramente rechazable es el discurso universalista, calificado habitualmente como una manifestación del deseo de imponer una cultura concreta sobre las demás ${ }^{25}$. Se produce una actitud de repulsa hacia las generalizaciones $\mathrm{y}$, por consiguiente, la afirmación de lo concreto histórico, sociológico o existencial. La vida no es susceptible de subsumirse ni en unos conceptos ni normas de carácter general y de validez universal, sin que exista una razón idéntica y valedera para todos los hombres.

No se predica más aquella identidad de contenido de la naturaleza humana ${ }^{26}$ que era uno de los presupuestos de la noción "moderna" de la ley ${ }^{27}$. Recíprocamente, las concepciones no relativistas son potenciales enemigos de la libertad y de la igualdad puesto que quien mantiene unos criterios como verdaderos puede pretender imponerlos a los demás ${ }^{28}$. En este sentido, las religiones, por su afán universalista, pueden ser sospechosas de fundamentalismo ${ }^{29}$. Con la exclusión del ámbito público de

En relación con esta materia, Vila-Coro, M. D. (2003). La bioética en la encrucijada. Madrid: Dykinson, p. 46; Serrano Ruiz-Calderón, J. M (2000). "Sobre el reconocimiento y regulación legal del derecho a la eutanasia". Humana Iura, No 10, pp. 111 y ss.

Krajewski, P (2001). "Diritto della morte, diritto alla morte". Apollinaris, No 74, pp, 185 y ss.

Dalla Torre, G. (1993) 16. En un sentido análogo, Bertolino, R. (1994) 39.

Ballesteros, J. (2000) 16.

García-Pelayo, M. (1999) 72 y ss. Analiza someramente las causas de este proceso en la p. 71.

Sobre las variaciones que supone sobre la actividad normativa este nuevo concepto de la identidad humana sujeta a cambios, nos detendremos en el apartado 2.2.

Vázquez García-Peñuela, J. M (1998). "Constitución, pluralismo y dignidad humana: en torno a las cuestiones fundamentales del Derecho eclesiástico español". $D E, N^{\circ} 2$, pp. 440 y ss.

Ballesteros, J. (2000) 17. En efecto, las creencias religiosas necesitan proyectarse al espacio público si queremos que el que las profesa pueda disfrutar de una vida coherente. Se trata de una actitud que trasciende lo cultural. Aunque comparta elementos con este factor, como es el deseo de transmitir las costumbres que han generado con el tiempo los colectivos culturales y/o religiosos, en el caso religioso se añade que las creencias y prácticas religiosas se convierten en una "espèce de totalitè de cohérence, sans laquelle sa personalitè [la del creyente] n'a pas d'unitè", por lo que se crea una corriente que une inescindiblemente lo 
estos peligrosos elementos se puede acabar imponiendo, sin opción al debate, lo que algún autor ha denominado el "monoculturalismo de lo trivial" 30 . En este contexto se devalúa el debate democrático, constreñido a girar en torno a propuestas infundadas, "formuladas sin convicción por quienes no las consideran dignas de ser abordadas con particular seriedad"31.

"La perspectiva postmoderna adquiere (lenta pero irresistiblemente) la convicción de que la ética no es universal, sino que se articula en una multiplicidad de singulares opciones morales. Sería vano el esfuerzo de intentar reconducir a la unidad, con la paciencia de la argumentación racional, todas las opciones singulares. El conflicto entre los distintos valores que presiden la ordenación del mundo parece inconciliable y, por otra parte, las opciones resultan más auténticas cuanto más se viven en el plano de la praxis y menos se debaten en el plano de la teoría" 32 .

En definitiva, el hombre postmoderno encuentra que todo es discutible, considera que no puede existir una verdad objetiva ni un punto de coincidencia común de pensamiento sobre una determinada materia, desembocando, en no raras ocasiones, en una cierta sensación de abandono, desconfianza y de desprotección ${ }^{33}$. Ni siquiera el pleno amparo que ofrecía la razón, hasta hace algunas décadas predicada como axioma y fundamento de la seguridad del hombre moderno, ofrece respuesta a todas las dudas. La razón parece que ya no lo explica todo, con lo que los principios racionalistas quiebran.

Ante esta situación, se produce una exaltación de lo jurídico. La dispersión ética existente provoca que sea difícil conciliar las distintas orientaciones. Se entiende que todas tienen un mismo valor y, por eso mismo, han de coexistir sin solaparse e incluso sin mezclarse para mantener su "integridad" o "pureza" 34 . El único modo de conciliar estas éticas es a través de un mecanismo externo basado en el acuerdo como es el Derecho $^{35}$. Ante esta situación, se presenta frecuentemente una sensación de necesidad de una seguridad moral que guíe sus propias acciones. Es en el ordenamiento jurídico donde se pretenden encontrar los criterios que col-

que se cree y lo que se hace, "lo interno" y "lo externo". Se entiende que es propio de una cultura ofrecer sentido a las distintas prácticas sociales. Pero la religión eleva esta pretensión a un grado máximo, lo que es una muestra de la riqueza de la fe que, sin embargo, puede ser también entendido como algo peligroso. Sobre ello, Meyer-Bisch, P. (2002). "Le droit à la liberté de conscience dans le champ religieux selon la logique des droits culturels". Revue de Droit Canonique, ańo 52 No 1, pp. 9-25, con el texto entrecomillado en la p. 12.

30 Ollero, A. (2006). Bioderecho: entre la vida y la muerte. Pamplona: Aranzadi, p. 200.

Ollero, A. (2006) 200

D'Agostino, F. (2000) 19.

Vila-Coro, M. D. (2003) 44.

Ballesteros, J. (2000) 18 y ss.

Dalla Torre, G. (1993) 14, 15 y 113; D'Agostino, F. (2000) 20-22; Vázquez GarcíaPeńuela, J. M (1998) 441 y 443. 
men su desorientación. El ciudadano encuentra que el Derecho positivo le ofrece la confianza que niega al Derecho natural ${ }^{36}$.

En este proceso, la ética se divide formando sistemas dispares. A su vez, se separa la moral del Derecho para que no haya confusión entre ambos y, que siendo así, este pueda regular la convivencia social, desde una lejanía respecto de la moral que se expone como la pretendida única salvaguardia de su neutralidad. No se puede producir, desde este momento, una relación entre el ser y deber-ser puesto que esta última es una categoría metafísica incognoscible. La apreciación de las cosas y de los comportamientos humanos no se basa en valores objetivos, sino en estimaciones subjetivas producidas por unos sentimientos de rechazo o de aceptación que dependerán de los momentos y situaciones concretas en que acaezcan $^{37}$. La separación entre la moral y el Derecho contribuye, pues, a alejar el espectro de una temida ética común vinculante para todos los ciudadanos que se convierta en fundamento de las normas jurídicas ${ }^{38}$. Las posibilidades de organizar autónomamente la propia vida aumentan en correspondencia con el grado de disminución de un tercero que emite criterios que vinculan el modo de actuación de cada persona o que es capaz de exigir conductas.

Se puede concluir este proceso que estamos examinando planteándonos estas dos cuestiones. La primera consiste en que es fácil constatar que el Derecho ha de basarse necesariamente en algún tipo de valores. No puede ser de otro modo porque la aprobación de normas implica necesariamente una decisión. Se descartan unas opciones y se afirman, en cambio, otras. Esa elección responde, en definitiva, a que una posibilidad se entiende que es mejor que otra. Es fruto de un juicio de valor basado en

BetTetini, A. (2003) 9.

Hervada, J. (2002). "Libertad religiosa y relativismo", en él mismo: Los eclesiasticistas ante un espectador. $2^{\mathrm{a}}$ ed. Pamplona: Navarra Gráfica Ediciones, pp. 61 y ss., principalmente 66 y ss. y 70-73. El "deber ser" es una categoría futura a la que aspiran a convertirse o adaptarse los hechos o situaciones existentes en el momento presente. El "deber ser" es, como indica su propia expresión, algo debido y que, como tal, se satisfará en un futuro. El "es" existe ya, pero el "deber ser" es un todavía-no, pero que debe realizarse. Esta tesis adquiere varias proyecciones. Una de ellas es el modo de entender la construcción de la propia ciencia jurídica. Esta se desarrolla en el ámbito del "deber-ser". No es, como la Historia, una ciencia de hechos, sino de análisis de lo que debe hacerse, de modo que no puede elevarse a norma un comportamiento aduciendo que es la conducta mayoritaria en la sociedad. En este caso estaríamos afirmando que lo que "es" (el hecho), también "debe ser", lo que constituye una falacia lógica porque del "es" se predica el "será" al mismo tiempo. Es decir, se estaría predicando de algo al mismo tiempo el presente y el futuro. Hervada, J. (1987). "Bases críticas para la construcción de la ciencia del Derecho eclesiástico del Estado". ADEE, III, pp. 26-28, y en Hervada, J. (1992). Lecciones propedéuticas de Filosofia del Derecho. Pamplona: EUNSA, pp. 62-66.

En este sentido, Souto Paz, J. A (2003). Comunidad politica y libertad de creencias. $2^{\mathrm{a}}$ ed. Madrid: Marcial Pons, p. 317. Véase asimismo Ollero, A. (2001). Democracia y convicciones en una sociedad plural. Pamplona: Navarra Gráfica Ediciones, p. 13 y ss., en relación con la progresiva diferenciación entre la ética pública y la ética privada. 
criterios ideológicos, religiosos, culturales o morales. Se abre, por tanto, el debate referente al modo de elegir el fundamento de las normas.

En segundo lugar, si el Derecho es el único instrumento apto para conciliar las distintas éticas existentes, es preciso dilucidar qué tipo de aplicabilidad tienen aquellas que no están previstas o reconocidas por el Derecho o, incluso más allá de esto, son contrarias a lo generalmente ordenado por aquel. Esta cuestión desemboca indefectiblemente en que nos planteemos qué grado de admisibilidad tienen las objeciones de conciencia en un contexto como el descrito.

A la primera de estas cuestiones se intentará dar respuesta en el apartado tercero. El otro interrogante se abordará, en cambio, en el cuarto. Antes de desplazarnos a los lugares indicados es necesario afrontar otros aspectos referentes a la relación entre Derecho y valores en la sociedad actual como es la actual valoración de la autonomía y de la dignidad humanas.

\section{(2.2) LA VALORACIÓN DE LA AUTONOMÍA Y DIGNIDAD HUMANA}

Si el Derecho se ha de limitar a garantizar la autonomía del individuo en las elecciones éticas podemos estar afirmando, aunque sea implícitamente, que se debe otorgar únicamente relevancia ética y jurídica al sujeto en circunstancias de decidir sobre sus valores y sus derechos. Lo que se encuentra como trasfondo de esta tesis es la nueva interpretación que la ética postmoderna ofrece a la dignidad humana en sustitución de la heredada de la tradición judeocristiana ${ }^{39}$. En este último contexto se entiende que el hombre nace con una dignidad que forma parte de su esencia y de la que no podrá ser despojado. La consecuencia es que el hombre, por ser digno, es indisponible y no se le puede instrumentalizar ni encontrarse sustituido en sus decisiones. Es así como se debería entender la dignidad desde el punto de vista jurídico y como fundamento del orden político y de la paz social ${ }^{40}$. Es decir, como la libre capacidad de autodeterminación de la persona. Más ampliamente, significa la libertad de decisión sobre las acciones que pretenda realizar u omitir y obrar en conformidad con ese criterio $^{41}$. Esto supondría, por lo demás, un freno al ejercicio del poder y al riesgo de que la norma jurídica $-\mathrm{y}$, por extensión podríamos pensar en cualquier elemento que afecte al hombre desde el exterior de su personainstrumentalice a la persona o pretenda transformarla ${ }^{42}$. En definitiva,

\footnotetext{
39 A. Ollero (2006) 60-64 y 106.

40 Artículo 10.1 de la Constitución española.

41 Fernández Segado, F. (2003). "La dignidad de la persona como valor supremo del ordenamiento jurídico español y como fuente de todos los derechos". Jus, No 2, pp. 213 y ss.

42 Fernández Segado, F. (2003) 207. Precisamente la dignidad humana exige el rechazo de cualquier posibilidad de utilización de una persona, incluida su instrumentalización como
} 
porque es digno, es autónomo. Su dignidad exige su inmediato reconocimiento, sin que quepa esperar que dependa de la aceptación de los demás.

La interpretación postmoderna ofrece, como contraste, un sentido distinto de la dignidad. Ahora su autonomía no depende de su dignidad, sino que se considerará digna a la persona que es autónoma y no se convierte en una carga para los demás. Esto desemboca en un desplazamiento hacia el exterior del concepto de dignidad y, en consecuencia, de la capacidad de decidir sobre sí mismo. Solo el hombre autónomo puede ser titular de la dignidad. Pero el grado de autonomía de cada cual depende del criterio de los demás. Por tanto, su dignidad y, con ello, su capacidad de decidir, dependerá de que terceras personas lo encuentren capacitado para ello. La dignidad no es ya innata, sino "conferida" o "heterónoma" 43 . Como resultado, "la vida humana podrá, sobre todo en sus fases iniciales y terminales, resultar disponible y encontrarse privada en la práctica de toda dignidad" 44 .

Esta situación conlleva el riesgo de que no se valoren adecuadamente determinados seres. Caso paradigmático es el tratamiento jurídico que recibe el embrión humano. Nos centraremos a continuación en esta cuestión. El Tribunal Constitucional español ha sido consciente de que aquel es merecedor de protección jurídica, pero solo sui generis, lo que ha contribuido a desplegar una serie de argumentaciones prolijas para explicarlo. El motivo causante ha sido la necesidad de compatibilizar el respeto al embrión, pero sin evitar, por una parte, que se vea con ello reducida la libertad de la madre a elegir, en determinados casos, si el embarazo ha de continuar o, por otra parte, que los embriones sobrantes puedan ser utilizados con fines científicos. El alto intérprete constitucional ha entendido $^{45}$ que el modo de compatibilizar las distintas pretensiones consiste

simple medio para los fines de una sociedad organizada en forma colectiva o tecnocrática. El individuo no puede estar al servicio de pretensiones de carácter absoluto, ya provengan del Estado, de un grupo de la sociedad o de otras personas, como indica STARCK, C. (2005), "Introducción a la dignidad humana en el Derecho alemán". Anuario Iberoamericano de Justicia Constitucional, No 9, p. 490. Asimismo, Starck, C. (2001). "El estatuto moral del embrión". RDGH, No 15 , pp. 139-149.

43 Ollero, A. (2006) 60-64 y 106.

44 Ollero, A. (2006) 62. Cursiva original. Uno de los criterios externos que acaban permitiendo enjuiciar el grado de dignidad de una vida es su "calidad". Resulta particularmente interesante observar que, normalmente, serán terceras personas quienes acaben dictaminando sobre esta cuestión, siendo el autodiagnóstico una excepción, especialmente en las situaciones más extremas, en Ollero, A. (2006) 221, 222 y 229. Son prácticas inadmisibles que han de ser evitadas por los poderes públicos. En estos casos, el Estado debe asegurar unas condiciones mínimas para una vida digna a favor de aquellos ciudadanos que no están en condiciones de desarrollarse personal o socialmente por enfermedades físicas o mentales y que no pueden mantenerse a sí mismos, como indica acertadamente STARCK, C. (2005) 493.

45 Tribunal Constitucional español. STC 116/1999, de 17 de junio, FJ cuarto y quinto. Por ello entiende que los no nacidos no pueden considerarse titulares del derecho a la vida, por mucho que no se les prive de toda protección constitucional. Sigue en este punto la tesis anteriormente sentada por el Tribunal Constitucional italiano que afirma expresamente 
en entender que el embrión viable, aun siendo un ser humano, no es una persona. Adopta, por lo demás, un concepto de persona propio del Derecho civil español en virtud del cual solo es tal el sujeto que ha nacido con forma humana y ha vivido desprendido del seno materno veinticuatro horas $^{46}$. Sin embargo, no discute que el embrión es un ser humano, por lo que alguna protección jurídica ha de merecer.

Nos encontramos, pues, ante la definición de un ser humano al que no se le considera persona o, lo que es equivalente, se le aprecia como una $\operatorname{cosa}^{47}$. Si se le considerara persona, sería pleno titular de derechos, incluidos los fundamentales como el derecho a la vida. Sin embargo, esta afirmación provocaría que no se le pudiera instrumentalizar, utilizándolo para actividades científicas, ni se le podría arrancar el derecho a la vida a través del aborto.

Sin embargo, a este ser humano impersonal se le atribuyen una tutela y algunos derechos, lo que provoca que nos encontremos ante la particular situación de una cosa con derechos o, visto desde otro ángulo, con unos derechos que, en realidad, no tienen verdadero sujeto ${ }^{48}$. Se llega de este modo a principios de compromiso como la manipulación o intervención mínima ${ }^{49}$. Si se tratara de una persona, no se podría efectuar ningún tipo de manipulación, ni en mayor ni en menor grado. Y si se tuviera ciertamente claro que el embrión es una cosa, no serían necesarias restricciones de este tipo. Por tanto, algo de "persona" ha de tener. Estos argumentos son el resultado de tratar al embrión fácticamente como una cosa, pero sabiendo que teóricamente este posicionamiento es discutible ${ }^{50}$.

que "non esiste equivalenza fra il diritto non solo alla vita ma anche alla salute proprio di chi è già persona, come la madre, e la salvaguardia dell'embrione che persona debe ancora diventare", en la sentencia de la "Corte Costituzionale" italiana 27/1975, de 18 de febrero, FJ único. Sin embargo, no por ello deja de afirmar el derecho a la vida del embrión, tanto en esta sentencia como en la sentencia de la "Corte Costituzionale" 35/1997, de 30 de enero, cuestión de la que su homólogo espańol se distancia.

Artículo 30 del Código Civil español. Se trata de un concepto de persona que, en los tiempos de la redacción del Código (1889), no pretendía tanto lograr la protección del nuevo ser humano, como una identificación del interlocutor jurídico con el fin de conocer quién era, efectivamente, sujeto dentro del tráfico jurídico. Sin embargo, hoy en día este criterio está desfasado desde el momento en que se puede conocer con los actuales medios científicos si tiene figura humana desde el segundo mes de gestación. Junto a ello, durante el tránsito de las veinticuatro horas, es ya digno de protección jurídica. Por otra parte, fijarse únicamente en el artículo 30 puede oscurecer la relevancia del artículo 29, según el cual al concebido se le tiene por nacido para todos los efectos que le sean favorables, siempre que luego nazca con las condiciones establecidas en el artículo siguiente. A esto se añade que el concepto penal de persona trasciende el nacimiento puesto que confiere protección directa como persona al no nacido. Sobre ello, Ollero, A. (2006) 31-37.

Ollero, A. (2006) 45-54 y 75-86.

Así se desprende de la STC 116/1999, FJ undécimo y decimosexto.

50 Ollero, A. (2006) especialmente pp. 50-54. En este sentido, Gabaldón López, J. (2001). "Libre desarrollo de la personalidad y derecho a la vida". Persona y Derecho, No 44, pp. 141 
Estos argumentos pueden servirnos de base para considerar extrańo el posicionamiento del Tribunal Constitucional español y del Tribunal Europeo de Derechos Humanos ante el feto por no satisfacer adecuadamente su derecho a la vida. El Tribunal Constitucional no concede al nasciturus la titularidad del derecho a la vida reconocido en el artículo 15 de la Constitución espańola, aunque sí concluye que es un bien constitucional protegido al amparo de dicho precepto ${ }^{51}$. Este pronunciamiento no deja de ser contradictorio con el criterio anteriormente mantenido por este mismo Tribunal cuando declaraba que la vida del nasciturus es un bien, no solo constitucionalmente protegido, sino que encarna un valor central del ordenamiento constitucional ${ }^{52}$.

A partir de aquí, la protección constitucional que recibe el nasciturus permanece reducida al cumplimiento por parte del Estado de una doble obligación: la de abstenerse de interrumpir o de obstaculizar el proceso natural de gestación, y la de establecer un sistema legal de defensa de la vida que suponga una protección efectiva de la misma ${ }^{53}$.

Por cuanto se refiere al Tribunal Europeo de Derechos Humanos ha declarado que el artículo segundo del Convenio de Roma de 1950, al reconocer el derecho a la vida, no especifica sus límites temporales, ni define qué ha de entenderse por "persona", a los efectos de localizar al titular del derecho ${ }^{54}$. Habrán de ser los Estados quienes, a través de sus legislaciones internas, definan cuándo se considera que comienza la vida. Indica el Tribunal que, en el contexto supranacional europeo, no hay consenso sobre la definición científica y jurídica sobre ello ${ }^{55}$.

Otro ejemplo de esta concesión de relevancia a las decisiones adoptadas solo por quien es capaz de decidir sobre sus valores y derechos podría ser el aprecio ofrecido al cuerpo humano ${ }^{56}$. Podría llegar a ser prácticamente irrelevante desde el punto de vista jurídico porque deviene, simple-

y 147 y ss. Consúltese también Serrano Ruiz-Calderón; J. M. (2005). Retos juridicos de la bioética. Madrid: Ediciones Internacionales Universitarias, principalmente pp. 175-199. Tribunal Constitucional Español. SSTC 53/1985 FJ séptimo; 212/1996, FJ tercero. STC 116/1999, FJ cuarto y quinto.

52 STC 53/1985, FJ noveno.

53 STC 212/1996, FJ tercero. Sobre esta cuestión, Ferníndez SEgado, F. (1986). "El derecho a la vida en la Jurisprudencia constitucional". Revista de Legislación y Jurisprudencia, № 6, p. 867.

54 Tribunal Europeo de Derechos Humanos. STEDH del caso VO contra Francia, de 8 de agosto de $2004, \$ 75$.

55 STEDH del caso VO contra Francia, de 8 de agosto de 2004 , especialmente $\$ \$ 82$ a 89. C. M. Romeo Casabona ha echado en falta una mayor profundidad en el contenido de esta sentencia. En su opinión, el Tribunal podría haber aprovechado esta ocasión para ser más explícito sobre el significado de la vida prenatal, estableciendo con más precisión su régimen jurídico, así como garantizar la protección efectiva de esta vida. Asimismo, Romeo CASABoNA, C. M. (2004). "El alcance del derecho a la vida en relación con el concebido según el Tribunal Europeo de Derechos Humanos". RDGH, No 20, pp. 163-173.

PaLAZZANi, L. (2002) 170 y ss. 
mente, un objeto a disposición de la persona que puede decidir sobre él. Se convierte en un objeto de la voluntad y de la subjetividad, perdiendo todo valor objetivo o esencial, encontrándose al servicio del sujeto que tiene capacidad de decidir autónomamente, aunque sea de un modo incluso arbitrario y reprobable para los demás. De este modo, no existe un deber objetivo de protección del cuerpo humano biológico y, por tanto, de la vida misma. Todo acabaría dependiendo de la voluntad y del modo que cada sujeto tenga de orientar su autonomía según los valores éticos de que participe en cada momento.

En definitiva, prácticas como la eutanasia están basadas, al menos en cierta medida, en este tipo de planteamientos. Desde el momento en que la subjetividad adquiere un protagonismo tal que se erige por encima de cualquier interpretación o planteamiento universal u objetivo de la misma vida y de su propio soporte físico que es el cuerpo, se admite que cada sujeto puede solicitar cualquier tipo de intervención sobre aquel, e incluso pedir que se practique el fin de su vida. Todo dependerá de qué sea aquello que pida o consienta, es decir, de su voluntad.

La cadena argumentativa puede llegar aún más lejos. Si triunfa hasta este grado el subjetivismo, de tal manera que solo puede decidir el sujeto con capacidad para ello y para guiar su vida de acuerdo con unos criterios éticos, se puede finalizar por proponer que quien no puede proceder de este modo no tiene por qué seguir viviendo. En efecto, los embriones, los fetos o los recién nacidos no son sujetos autónomos, no pueden apreciar su propia existencia, y no tienen capacidad de continuar su vida si alguien no impulsa este proceso. El derecho a la vida se puede acabar convirtiendo en un derecho propio de la subjetividad autónoma-siempre que se tenga esa subjetividad autónoma- o de la persona que quiere vivir, prescindiendo de su corporeidad biológica. Un cuerpo, aun humano, sin subjetividad, carecería de valor ${ }^{57}$.

La exposición de estos planteamientos, aun siendo algunos de ellos extremos, puede ser útil, aunque sea solo como advertencia de determinados riesgos. Sin embargo, es cierto que parte de las situaciones descritas no se producen. Prueba de ello es que, a pesar del creciente subjetivismo, se protege la vida de los discapacitados o de los recién nacidos, por lo que el Derecho no ha llegado a identificarse, al menos plenamente, con un instrumento formal neutral del sujeto autónomo. Incluso el Tribunal Constitucional español ${ }^{58}$ ha reconocido el valor de la vida prenatal y la necesidad de su protección, aunque paradójicamente lo haya afirmado en una sentencia que despenaliza parcialmente el aborto. 
Estas tendencias podrán superarse si se considera que el Derecho goza de un carácter vehicular entre las personas. No ha de estar tan lejano de ellas como para garantizar únicamente la autonomía de cada uno y de la pluralidad social, sino que puede ser portador de unos valores objetivos que han de ser comúnmente respetados. Uno de esos criterios comunes consistirá en reconocer al cuerpo y a la vida como portadores de un valor objetivo $^{59}$. Se trata de que el Derecho, al menos en materia de bioética, no sea tan estrictamente neutral.

\section{3) LA ACTIVIDAD LEGISLATIVA Y EL CONTENIDO OFRECIDO A LA NORMA JURÍDICA}

\section{(3.1) EL ESPACIO JURÍdico RESERVADO A LOS VALORES Y LA ACTITUD DE LOS PODERES PÚBLICOS ANTE ELLOS}

El pluralismo ético no debe considerarse contrapuesto a la existencia de unos valores universales, sino que ha de tratar de compatibilizar el respeto entre las diferentes tendencias. De este modo se conseguirá que esa pluralidad ética no impida llevar a cabo una valoración moral de un supuesto concreto prescindiendo forzosamente de principios o valores universalmente aceptables. El pluralismo, por tanto, no requiere necesariamente como soporte intelectual el relativismo ${ }^{60}$.

Junto con la dificultad de encontrar unos criterios de actuación y regulación comunes, surge otra cuestión consistente en las suspicacias y recelos que, en ocasiones, parecen provocar aquellas opciones que coinciden con los postulados éticos o morales de concretas corrientes filosóficas o religiosas. Una interpretación forzada de la neutralidad religiosa del Estado $^{61}$ sería susceptible de hacernos entender que las opciones legislativas no pueden coincidir con los postulados de una de las mencionadas corrientes dado que esta situación es sospechosa de un favoritismo o privilegio hacia la confesión religiosa con que se coincide ${ }^{62}$. Si se afirmara

PalazZani, L. (2002) 173-177.

Vázquez García-Peñuela, J. M. (1998) 440 y 443. Cuestiones también tratadas en González-Varas Ibáñez, A. (2008). "La proyección jurídica del pluralismo religioso". $A D E E$, XXIV, pp. 387-409.

La actitud neutral que ha de guardar el Estado frente a lo religioso deriva del artículo 16 de la Constitución española donde se reconoce el derecho fundamental de libertad religiosa, la aconfesionalidad del Estado y el principio de cooperación del Estado con las confesiones religiosas.

Martín Sánchez, I. (2005). "Bioética y libertad religiosa”, en AA. VV.: Bioética, Religión y Derecho. Madrid: Fundación Universitaria Espańola, pp. 217 y ss. Ollero, A. (2001) 40 y ss. Roca, M. J (2005). "Teoría' y 'práctica' del principio de laicidad del Estado. Acerca de su contenido y su función jurídica". Persona y Derecho, No 53, p. 245. También se detiene en esta cuestión Navarro Valls, R. (1993). "Los Estados frente a la Iglesia". ADEE, IX, pp. 33 y ss. Asimismo, González-Varas Ibáñez, A. (2008) 387 y ss. 
esto, no sería difícil llegar a sostener que, aunque sea de una manera más o menos velada, se estaría produciendo, de hecho, incluso una situación de verdadera confesionalidad. La única solución posible para evitar estas situaciones parecería consistir en evitar que las opciones legislativas coincidieran con la doctrina mantenida por esa confesión religiosa, con lo cual se producirían, con toda probabilidad, una serie de efectos concatenados.

En primer lugar, es posible que, al no querer asumir el "riesgo" de identificarse -o más bien, coincidir- con una determinada doctrina religiosa, se esté actuando en contra de un criterio generalmente difundido en la sociedad. Es probable que el criterio social tenga un origen religioso, como tantas veces sucede, pero la sociedad lo mantiene quizá no tanto por respeto o afinidad a ese credo, sino porque su contenido ha pasado, tras su proceso de secularización, a formar parte de la cultura de la sociedad y así configurados encuentran cabida en el ámbito jurídico. Se produce una secularización de los valores religiosos, pero no una exclusión de sus reflejos jurídicos ${ }^{63}$. Por tanto, los órganos legislativos, que se entiende que representan al pueblo, acabarían contraviniendo lo que ese pueblo genéricamente comparte o, lo que es lo mismo, actuarían en contra del pueblo que legitima su existencia. En atención a este criterio, cuando se constata que se aprueban normas cuyo contenido afecta a la conciencia o creencias humanas, y producen el rechazo de amplios sectores sociales, podemos estar ante un indicio de quiebra en el sistema de producción legislativa o de conexión entre el legislador y la sociedad ${ }^{64}$.

Este modo de actuar parece desconocer que, cuando se trata de regular situaciones que afectan a la esencia propia del ser humano, como son su dignidad o el concepto de la vida humana, suele haber una coincidencia entre las distintas religiones, así como con el criterio de una multitud de personas que no profesan religión alguna. Se pretende afirmar con

63 Navarro Valls, R. (1993) 40. Por otra parte, es cierto que la cultura occidental es una cultura laica y secularizada desde el momento en que no toma en cuenta los valores cristianos en cuanto religiosos, pero no deja de ser verdad que continúa permeada por los valores cristianos puesto que no los ha sustituido por otros. Sobre ello, VEGA Gutiérrez, A. M. (1996). "Bioética y Derecho: razón y ética versus razón ética", en Goti Ordeńana, J.: Secularización y laicidad en la experiencia democrática moderna. San Sebastián: Librería Carmelo, pp. 214 y ss.

64 Por ello resulta llamativo que la objeción de conciencia, que se entiende que habría de afectar a grupos sociales minoritarios, se convierta en un fenómeno socialmente extendido. A partir de este hecho, entiende Ruiz Miguel que "el carácter excepcional de la objeción se correlaciona habitualmente con el rasgo de protección de las minorías religiosas y similares: de otro modo, si la objeción fuera generalizada entre la población, la propia técnica jurídica de imposición de un deber general se mostraría, cuando menos, como programáticamente inadecuada para conseguir los objetivos buscados, que deberían reformularse políticamente o, en todo caso, intentarse por otras técnicas", en Ruiz Miguel, A. (1996). "La objeción de conciencia, en general y en deberes cívicos". Revista Española de Derecho Constitucional, № 47 , p. 16. 
estas palabras que nos encontramos ante situaciones tan básicas sobre el concepto del hombre, que son universalmente aceptadas. Por tanto, si los poderes públicos se muestran reticentes a aplicar una determinada política motivados por el temor a coincidir con la doctrina de una concreta confesión pensando que transgreden su debida neutralidad religiosa, es muy probable que procedan en contra de lo que sostiene no solo esa confesión, sino la mayoría de las religiones que existen y del criterio de una multitud de personas que no profesan religión alguna.

No se puede desconocer que la actividad de los poderes públicos y, en concreto, la legislativa, responde necesariamente a algún tipo de criterio o de valores desde el momento en que en la misma sociedad de que provienen y a la que sirven existe una ética o unos valores generalmente compartidos, independientemente del origen que estos tengan ${ }^{65}$. Si su criterio no puede coincidir con el mantenido por una cierta confesión religiosa (que, como se ha afirmado, podrán ser varias religiones distintas), se encontrará sustituido por otro contenido distinto que es el efectivamente elegido. Se puede llegar, de este modo, a una situación de "dogmatismo ideológico" que muestra una acción tan poco neutral del Estado como lo es el "dogmatismo religioso" 66 . En definitiva, la actuación del Estado responderá siempre a algún principio o valor que lo inspira. En su elección podrá acertar o errar, pero deberá realizar alguna opción. Su elección será en todo caso errónea cuando esté fundada en una verdad que no sea acorde con lo que es el propio hombre ${ }^{67}$.

Según Navarro Valls, lo que se critica es que, escudándose en la laicidad, el Estado llegue a postular un relativismo ético. No puede llegar a producirse toda disociación de la democracia de toda objetivación de valores de la persona. El Estado no puede abandonar el humus histórico al que debe su propia consistencia o que olvide el patrimonio estable de verdades que no está sometido a consenso, sino que precede al Estado y lo hace posible, como afirma Navarro Valls, R. (1993) 33 y ss.

Sobre ello, Navarro Valls, R. (1993) 34, quien explica la génesis de esta actitud fundamentalmente desde la p. 23. Advierte este autor que "no conviene olvidar que al marginarse, en lo social las creencias religiosas, el hueco de estas ha sido ocupado por las ideologías, to cual no tendría nada de especial si no fuera porque estas han tendido con demasiada frecuencia a convertirse en [...] 'cuasi religiones' y, correlativamente, a incidir en parecidos o mayores excesos que las religiones tradicionales", en NaVArro Valls, R. (1993) 23 in fine. En este sentido Dalla Torre, G. (1993) 16 y 24. En relación con las consecuencias de semejante actitud, pp. 34-41. La primera de ellas es lo que el autor denomina "antimercantilismo moral", consistente en el miedo de las Iglesias y sus fieles a mostrar sus criterios públicamente como consecuencia de que se les tache de intolerantes o sujetos socialmente peligrosos. La segunda la constituye el riesgo del fundamentalismo. En relación con estas cuestiones, Ollero, A. (2001) 44-54 y 63-76. gelium Vitae e Diritto'”. IC, No 72, pp. 715-743, particularmente p. 716. 
Cabe ańadir, como ha sostenido parte de la doctrina ${ }^{68}$, que las aportaciones de las confesiones religiosas en el momento de establecer los criterios que han de guiar la regulación en varios ámbitos, pueden ser positivas $y$, en todo caso, han de tenerse en cuenta, siempre que no constituyan su fundamento exclusivo. No es digno de olvidarse que aportarán nuevos enfoques al mínimo común ético compartido en cada materia. Si permaneciéramos anclados en unos principios mínimos consensuados, se correría el riesgo de caer en el estancamiento, evitando cualquier evolución en la actividad legislativa. Por ello, las aportaciones de las confesiones religiosas pueden enriquecer el debate, abriendo nuevas perspectivas. Puesto que proponen completos sistemas morales sobre la vida, invitan a elevar la ética de mínimos propia del ámbito civil, a unas nuevas aspiraciones de máximos.

\section{(3.2) EL CONTENIDO DE LA LEY: LA PROPUESTA DE LA SOCIEDAD AL LEGISLADOR, O DEL LEGISLADOR A LA SOCIEDAD}

De acuerdo con lo afirmado hasta ahora se puede entender que el verdadero riesgo para la neutralidad de las decisiones de los poderes públicos no parece que radique tanto en que la opción legislativa coincida con un credo religioso -que es al mismo tiempo "cultura civil"-, sino que los poderes públicos aprovechen la posibilidad de legislar para convencer a ese pueblo de que ya no tiene esas ideas. El resultado sería que la ley ya no refleja la voluntad del pueblo, sino que la transforma. A partir de este momento, el carácter discutible de la decisión política, o la falta del necesario consenso en torno a ella, aparece colmado por el efecto legitimador de la norma jurídica aprobada según las oportunas reglas procedimentales. El carácter instrumental del Derecho sigue existiendo, solo que cambiado de signo: no es ya un modo de expresar los valores éticos de la sociedad destinados al logro de la justicia y de la limitación del poder político, sino una expresión de los criterios políticos que buscan, a través del Derecho, la transformación de la ética a su medida. La legitimidad de la actuación de los poderes públicos ya no parece derivar, en esta sociedad postmoderna en que no hay asideros conceptuales, éticos ni morales estables, de la necesidad de la consecución del bien común o de la justicia, sino de la toma de decisiones por mecanismos democráticos. Por tanto, cualquier decisión adoptada según el procedimiento debido, deberá ser aceptada, pasando su contenido a un plano secundario ${ }^{69}$. Paradójicamen-

\footnotetext{
68 Dalla Torre, G. (1993) 25; Martín Sánchez, I. (2005) 222, 223, 228, 229;. Martín Sánchez, I. (2005). "Bioética y religión", en él mismo (Coord.): Bioética, Religión y Salud. Madrid: Comunidad Autónoma de Madrid, pp. 38 y ss.

69 De Fuenmayor, A. (2003). La inspiración cristiana de las leyes. Pamplona: Instituto Martín de Azpilcueta; Ollero, A. (2006) 192-194, 237 y ss. Este planteamiento supondría un
} 
te, el aspecto procedimental se eleva al principal grado de importancia, quedándole subordinado lo material o sustancial.

Si se constatara que la toma de decisiones por los órganos competentes se desarrolla en estos términos, estaríamos exacerbando los planteamientos de origen formalista que han contribuido a forjar algunos de los postulados de la moderna Teoría de la Constitución. Si examinamos los postulados de Forsthoff, es cierto que sostiene que la concepción del parlamentarismo como un servicio a la razón y de las leyes como ratio y no voluntad fue propio de tiempos anteriores ${ }^{70}$. Es más, considera que la concepción del parlamento se ha transformado con el paso del tiempo, de modo que "no significará hoy otra cosa que el procedimiento por el que se transforma a la decisión mayoritaria en voluntad estatal vinculante" 71 . Ańade que la formación de la voluntad del parlamento depende de cuanto sostengan los partidos políticos ${ }^{72}$. A su vez, su criterio dependerá de la influencia que proyecten sobre ellos los distintos grupos de intereses organizados de tal manera que existe el peligro "de que sea el potencial organizativo de los participantes y no los argumentos objetivos los que prevalezcan y determinen dando la victoria al mejor organizado" 73 .

Estas afirmaciones no obstan que el mismo autor mantenga que, dentro del Estado social, la sociedad y éste no se encuentran separados, como sí sucedía durante el Estado de Derecho liberal ${ }^{74}$. Más aún, el Estado social se basa en la participación de la sociedad en el Estado ${ }^{75}$. Con este postulado se supera la hasta entonces mítica división entre Estado

claro distanciamiento de los orígenes del principio mayoritario tal como lo configuró el Derecho canónico medieval. En este contexto se relacionó la regla de las mayorías con una mayor seguridad de encontrar la verdad a través de la concurrencia de las voluntades, tal como se estudió anteriormente en González-Varas IbáńEz, A. (2007). Consejo y consentimiento en los órganos colegiados canónicos. Su incidencia en el Derecho Público secular medieval. Valencia: Tirant lo Blanch y bibliografía allí citada.

Forsthoff, E. (1986). "Problemas constitucionales del Estado social", en AA. VV.: El Estado social. Madrid: Centro de Estudios Políticos y Constitucionales, p. 56.

71 Forsthoff, E. (1986) 56. Forsthoff fue uno de los principales autores que rechazaron el denominado método de las ciencias del espíritu que había surgido en Weimar como una opción frente al formalismo del método jurídico positivista y logicista que excluía lo metajurídico. Por eso consideró que el pensamiento jurídico de valores suponía inseguridad y arbitrariedad. Sobre ello, Gallego Anabitarte, A. (1992). "Derechos fundamentales y garantías institucionales: una recepción jurídico doctrinal", estudio preliminar a la obra de Díaz Lema, J. M.: Los conciertos educativos en el contexto de nuestro Derecho nacional, y en el Derecho comparado. Madrid: Marcial-Pons, p. 10. FORSTHOFF, E. (1986) 57 y 59.

FORSTHOFF, E. (1986) 59.

Forsthoff, E. (1986 a). "Concepto y esencia del Estado social de Derecho", en AA. VV:: El Estado social, Madrid: Centro de Estudios Políticos y Constitucionales, p. 81. 
y sociedad ${ }^{76}$. Esto es consecuencia de las propias funciones que aquel asume. Se encarga de recibir parte de las propiedades de las personas, las redistribuye $\mathrm{y}$, de este modo, asegura la prestación de medios o servicios públicos que aseguran el disfrute de los bienes materiales necesarios para vivir $^{77}$. Se entiende que el ciudadano tiene derecho a expresar sus criterios sobre el modo de realizarse esa distribución, pues de él provienen los recursos utilizados por los poderes públicos y tendrá que exponer cuáles son las necesidades que deben cubrir. Para lograr su adecuada consecución es necesario que el Estado recuerde que las funciones que le corresponden son de servicio o de carácter social.

El resultado es que la participación se convierte en un derecho o pretensión ${ }^{78}$. Lo contrario podría dar lugar a que sus funciones se conviertan en instrumentos de poder ${ }^{79}$. De este modo se defiende una conexión entre la sociedad y el Estado que pondrá a este al servicio de aquella. Se trata de un planteamiento que, aun mostrando un cierto escepticismo hacia el sistema parlamentario como consecuencia del dominio de las mayorías, defiende la participación social como parte esencial del funcionamiento del Estado.

Se puede añadir que, si defiende esa implicación partiendo de unas funciones estatales de carácter fundamentalmente material, como es la provisión de bienes materiales necesarios para vivir o procura existencial (Daseinsvorsorge), con mayor motivo podría hacerse cuando la toma de decisiones afectan al espíritu humano, lo que está revestido de particular delicadeza.

La justificación de una decisión normativa a partir de criterios procedimentales sería más difícil de conciliar con la otra corriente doctrinal que ha fundamentado la moderna Teoría de la Constitución. Nos referimos a las tesis integradoras de Rudolf Smend donde el contenido de la Constitución y de las leyes son fundamentales para su validez y legitimidad. Frente a la dogmática del positivismo jurídico, entiende que el Poder Legislativo desarrolla una actividad "material" determinada por su valoración desde el punto de vista de la justicia ${ }^{80}$. La ley legitima la actividad del legislador cuando pone al Estado en "una relación íntima con el mundo de los valores" históricamente válidos y que trascienden al propio

\footnotetext{
76 Cossio Díaz, J. R (1989). Estado social y derechos de prestación. Madrid: Centro de Estudios Políticos y Constitucionales, p. 32.

77 Principalmente en E. Forsthoff (1986) 49; E. Forsthoff (1986 a) 86; E. Forsthoff (1967) 69 y ss.

78 ForsthofF, E. (1986) 86.

79 Forsthoff, E. (1986 a) 51 y ss. Indica en la p. 52 que la instrumentalización de las funciones sociales con fines de dominación ha sido lo que ha ocurrido en los países comunistas. E. FORSTHOFF (1967) 50.

80 Smend, R. (1985). Constitución y Derecho constitucional. Madrid: Centro de Estudios Políticos y Constitucionales, p. 158.
} 
Estado y a su ordenamiento jurídico ${ }^{81}$. Si no existe esta legitimación, la norma no es válida ${ }^{82}$.

Para entender adecuadamente esta propuesta hemos de tener en cuenta que, según este autor, el Estado es una realidad espiritual ${ }^{83}$. Más exactamente, es una realización cultural que como tal realidad de la vida del espíritu es fluida, necesita continuamente de renovación y desarrollo. Esto se consigue a través de la constante acogida y asimilación de sus miembros que, al ser parte de la realidad espiritual no constituyen sustancias estáticas, sino una unidad de sentido de actos espirituales ${ }^{84}$. Junto con la realización de los valores del espíritu, le corresponde al Estado dictar el Derecho positivo, pero esta segunda acción ha de llevarse a cabo en íntima conexión con la primera. El orden jurídico positivo depende de los elementos esenciales constitutivos del Estado ${ }^{85}$ que, en términos amplios, se reflejan en la Constitución como documento que recoge la dinámica vital en que se desarrolla la vida del Estado ${ }^{86}$. Si la Constitución abarca la totalidad del Estado y del proceso integrador, los distintos actos normativos son positivizaciones concretas de las posibilidades y funciones propias del mundo del espíritu ${ }^{87}$. El sentido que adquiere la actividad normativa no es el de una simple regulación de "una estructura dada y permanente, y de sus manifestaciones exteriores, sino que es la forma que da fundamento a dicho grupo y le permite su continua creación y renovación" 88 .

Volviendo al inicio del planteamiento de Smend, se puede concluir que la actividad legislativa es un poder propio del Estado. Al mismo tiempo, la ley le legitima cuando consigue reflejar su contenido espiritual en el ámbito regulado. Por tanto, un concepto puramente formal o positivista de la norma no llegaría a ser fuente legitimadora, a la vez que supondría una visión un tanto depauperada. Como él mismo afirma, "la formalización de la ley, reflejada en su introducción como poder legislativo en las Constituciones positivas tuvo como consecuencia irremediable el empo-

SMEND, R. (1985) 159 y ss., y 166.

SMEND, R. (1985) 166.

SMEND, R. (1985) 56.

SMEND, R. (1985) 61-64.

SMEND, R. (1985) 66.

SMEND, R. (1985) 132-136. En esta función integradora cobra particular relevancia la parte programática de la Constitución, que en la de carácter estrictamente jurídico destinada a ofrecer instrucciones precisas para la gestión de los órganos del Estado. Precisamente por esa función de integración, los políticos encargados de elaborar proyectos constitucionales tienden a sobrecargarlos con palabras programáticas pensando que de este modo se pueden ofrecer soluciones a difíciles problemas sociales, como indica Starck, C. (2003). "La legitimación de la justicia constitucional y el principio democrático". Anuario Iberoamericano de Justicia Constitucional, $\mathrm{N}^{\circ} 7$, p. 488.

SMEND, R. (1985) 66 y 133.

SMEND, R. (1985) 137. 
brecimiento del contenido de este concepto y la puesta en duda, debido a su significado inmanente, de su fuerza legitimadora" 89 .

De un modo u otro, parece que no se adecua cómodamente con la Teoría de la Constitución una tesis que defienda la legitimidad de la norma apelando principalmente a un criterio procedimental. Es cierto que no siempre será fácil reconocer cuándo los principios son sustantivos y cuándo meramente procedimentales ${ }^{90}$. Aun así, sería oportuno buscar un mayor equilibrio entre el aspecto procedimental y el material. En este orden se muestra atractiva la propuesta de Starck en el momento de afirmar que el procedimiento está ordenado a garantizar una cierta bondad del contenido de la ley ${ }^{91}$. El procedimiento legislativo está configurado en aras de facilitar el acceso a muchas y competentes reflexiones y propuestas que puedan influir en la determinación del contenido de la ley. Garantiza, en definitiva, informaciones sobre las situaciones reales que debe regular la ley, así como argumentos y consideraciones acerca de si la ley aspira realmente al bien común ${ }^{92}$. En un modo más cercano a la trayectoria definida por Smend que a la de Forsthoff, considera que el resultado de esta proporcionalidad, entre el procedimiento legislativo y el contenido legal, desemboca en que la ley aparece como una regulación fundamental e importante producida en un procedimiento cualificado, que constituye una cierta garantía de racionalidad y justicia de la misma ${ }^{93}$.

Ofrecer al Derecho un sentido primordialmente "formal" sobre el "sustancial" desemboca en que este último sentido quede sometido a la forma. Si fuera así, la definición de bien común o de justicia quedaría sometida a lo que el poder decidiera ${ }^{94}$, con tal de que lo hiciese dentro de esos cauces procedimentales que lo separan de cualquier criterio de enjuiciamiento objetivo y externo al propio poder. Con esta medida el Derecho adquiere una dimensión "autorreferencial", es decir, que lo hace depender solo de sí mismo o, lo que es sinónimo, del poder que lo crea ${ }^{95}$.

Este concepto del poder y del modo de legislar que analizamos favorece, asimismo, que se pueda estudiar el Derecho desde un punto de vista empírico o experimental. Se le podrá examinar, seccionar, recomponer o cuantas actuaciones sean necesarias para asegurar su efectivo cumplimiento. Se trata, pues, de un "strumento empirico per il perseguimento di fini

\footnotetext{
89 SMEND, R. (1985) 166.

90 Cossio Díaz, J. R. (1989) 34 y ss.

91 Starck, C. (1979). El concepto de ley en la Constitución alemana. Madrid: Centro de Estudios Políticos Constitucionales, p. 240. Starck, C. (2004). "Consenso fundamental nacional y Tribunales constitucionales (una reflexión jurídica comparada)". Anuario Iberoamericano de Justicia Constitucional, $\mathrm{N}^{\circ} 8$, especialmente p. 542.

Lo Castro, G. (1997) 6, 88 y 89.
} 
pur essi empirici"96. Esta situación confiere al Derecho un carácter contingente $\mathrm{y}$, al mismo tiempo - y en relación con la persona- cada norma es susceptible de interpretarse como un factor que, aun necesario, se limita a diseñar objetivamente su dimensión relacional, pero como un hecho que constriñe desde el exterior que no puede ser valorado en términos absolutos, sino provisionales y de conveniencia o utilidad ${ }^{97}$.

Si nos detenemos en examinar la influencia que este planteamiento formalista proyecta sobre el individuo y su conciencia, objeto principal de estudio por nuestra parte, se observa que el ordenamiento no adquiere como punto de referencia primordial al individuo ${ }^{98}$. Esto da lugar a que se produzcan normas que no tengan en cuenta su conciencia, con la consiguiente posibilidad de conflicto con esta. Con ello se le obliga al individuo a optar por una de estas dos soluciones: doblegar su conciencia a la ley o, de otro modo, objetar.

En conclusión, descubrir cuál es la relación entre el Derecho y el destinatario de la norma pasa por dilucidar si entendemos que la sociedad está compuesta por individuos aislados y diferentes, o si existe una verdadera comunidad con la que se puede identificar el Estado. La primera opción permitiría un mayor distanciamiento entre los poderes públicos y esos elementos sociales. La segunda, llevada a su último extremo, daría lugar a una identificación entre poderes públicos y sociedad que, a través de su íntima conexión, podría llegar a desconocer la existencia de la persona individualmente considerada y entenderla como uno de los múltiples elementos que conforman el tejido social.

Entre ambos extremos puede estar el término medio adecuado. Por una parte, no sería fácil aceptar que la sociedad es un bloque monolítico. Existen unos valores comunes que es necesario descubrir. Pero también ocurrirá que cada persona puede presentar un concepto determinado de su propio ser que no puede ser absorbido por la comunidad. Este planteamiento acabaría haciendo sucumbir a la persona dentro del torbellino social. Por ello, es oportuno dejar una vía de escape al individuo cuando, por un motivo serio y permisible, no comparta alguno de los elementos comunes a la sociedad.

No se pretende, empero, formular una apología del subjetivismo. El individuo no es un ser aislado que se encuentra imposibilitado para formar parte de una comunidad. Esta ciertamente existe y se encuentra dotada de unos valores comúnmente compartidos. La persona singularmente considerada es el centro de la atención de toda actividad, pero el contexto en que vive es el social. Incluso cuando se propugna una función del Es-

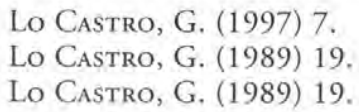


tado como un ente más alejado de la sociedad, como un ordenador de recursos que proporciona bienes necesarios para vivir, se afirma que se ha de contar con la opinión social, aunque solo sea porque esos bienes que redistribuye provienen de ella. Por tanto, no puede decidir de cualquier modo, sino de acuerdo con la sociedad que produce esos recursos y que, al mismo tiempo, la sirven. Las funciones del Estado no se convertirán en instrumentos de poder, abusando de la incomunicación entre las personas, porque esa relación entre los individuos existe y se han de tener en cuenta los criterios mayoritariamente compartidos.

Sería oportuno que el Estado optara por legislar con el afán de responder a expectativas e instancias de los sujetos. De este modo la legislación adquiriría su necesaria dimensión ética y, a su vez, permitiría que la conciencia individual se determinase libremente y el hombre pudiera actuar conforme a ella. Para ello es necesario que el legislador acepte que el procedimiento es un medio que existe en función de este objetivo. El sistema legislativo basado en la aprobación de las normas en aplicación del principio mayoritario debe ser entendido como una ocasión de debate destinado a encontrar los elementos comunes de las distintas propuestas y alternativas. Es así como los poderes públicos pueden realizar su función propia de servicio a la sociedad y al bien común.

Entender el sistema de mayorías como un medio para aprobar textos que, con independencia de su contenido, hayan de ser cumplidos por los ciudadanos, convierte al procedimiento en un arma al servicio del legislador. Se muestra como un instrumento idóneo del que este se puede servir para trasladar a la sociedad lo que estima oportuno, independientemente de que sea más o menos conveniente para el destinatario, o de que lo acepte de mejor o peor grado.

\section{(3.3) LA LEY ENTRE DERECHO Y POLÍTICA}

Cabe indicar que una indebida desatención al elemento ético de la ley y de la persona y, en contrapartida, un exceso de concentración en los elementos procedimentales de aprobación de la ley, produciría una preponderancia del voluntarismo jurídico y una omnímoda hegemonía de la ley. Con ello se invertiría, centrándonos en el caso español, el planteamiento presentado desde la Ley de Reforma Política ${ }^{99}$ que facilitó la Transición. Consistió en que el nuevo régimen democrático que habría de consolidarse debería garantizar la inviolabilidad de los derechos fundamentales de la persona y la vinculación a ellos de los órganos del Estado.

En efecto, a partir de ese momento, el poder no podía concebirse, en sus orígenes y en su ejercicio, sino limitado. Se proponía "un rechazo de 
cualquier cobertura formalmente democrática frente a la arbitrariedad de una mayoría contraria a los más elementales valores inherentes a la persona humana, y una reafirmación de que la persona no es un mero reflejo de la ordenación jurídica, sino que, bien al contrario, tiene una existencia previa" 100 . A partir de aquí, la dignidad humana adquiere una función legitimadora del orden político en su conjunto. Precisamente por ello, se presenta como un valor supremo del ordenamiento jurídico ${ }^{101}$, que junto con los derechos inviolables inherentes a la persona y las libertades públicas se erigen en fundamento del orden político y de la paz social, tal como establece la Constitución española en su artículo 10.1.

Con esta declaración la Constitución está recogiendo lo que no es del todo habitual en otros textos constitucionales: el contenido objetivo de los derechos fundamentales ${ }^{102}$. Estos aparecen reconocidos no solo como unos derechos subjetivos, sino también como unos valores o principios superiores del ordenamiento jurídico y fundamento del orden político y jurídico mencionado. Esta afirmación no goza de un mero carácter testimonial. Antes bien, despliega una serie de consecuencias jurídicas de alto alcance que impregnan todo el ordenamiento jurídico. Aunque este no sea el momento de detenerse en estas cuestiones, sí es oportuno indicar, entre ellas ${ }^{103}$, que los poderes públicos no solo tienen que evitar que se violen esos derechos, sino que han de garantizar que las libertades públicas sean efectivas a través de la aprobación de las pertinentes normas. A ello se añade que tendrá que preocuparse, como indica el artículo 9.2 de la Constitución española, de remover los obstáculos que impidan o dificulten el pleno e igual disfrute de los derechos fundamentales y de las libertades públicas. De aquí puede inferirse que el respeto al contenido de estos derechos y libertades debería servir de límite a la actuación de los poderes públicos, y la garantía de su ejercicio debería ser uno de los criterios que orientasen su actividad.

Estas tesis nos permiten entroncar con el siguiente eslabón de esta línea argumental. En efecto, una consecuencia añadida de los planteamientos en que predomina el aspecto procedimental de las normas sobre el material consiste en que, en los actuales Estados de Derecho, el ordenamiento jurídico no tendría ya como función primordial la de limitar

100 Fernández Segado, F. (2003) 207.

101 Fernández Segado, F. (2003) 217 y ss. Véase también Roca, M. J. (2005). "Diversidad cultural y universalidad de los derechos: retos para la fundamentación del Derecho". Anuario Iberoamericano de Justicia Constitucional, N 9, pp. 357-377, principalmente pp. 360 y ss.

Gallego Anabitarte, G. (1992) 38. Este despliegue del contenido en una vertiente subjetiva y en otra objetiva afecta a los distintos derechos fundamentales. Por cuanto se refiere a uno de ellos, como es la libertad religiosa, explica las distintas proyecciones de cada sentido González Moreno, B. (2005). "Delimitación del objeto del Derecho eclesiástico". ADEE, XXI, pp. 138 y ss.

103 Desarrolla esta tesis Gallego Anabitarte, G. (1992) 38-40. 
el poder, encauzando su actividad por unas vías previstas. Antes bien, el Estado, privado de una ética o moral objetiva que lo limite desde fuera, es puro poder, e incluso poder creador -a través de la norma- de una ética o moral, o de lo que se entiende por justicia ${ }^{104}$. Podría alejarse del contenido de esos derechos y libertades fundamentales que lo legitiman y, al mismo tiempo, limitan su actuación, con tal de que así lo decida siguiendo los mecanismos de expresión de su voluntad previstos. Con ello tergiversaría los propios valores que lo sustentan y dan sentido a la actuación normativa.

Derecho y justicia se acabarían convirtiendo "en instrumentos técnicos que reflejan [...] la verdad moral que está en la fuerza"105. Su función se traduce en la justificación de la actividad de los poderes públicos y de las decisiones políticas. Por tanto, el Derecho habría de seguir forzosamente a la política, mostrando a la ciudadanía que, si la norma jurídica existe, es porque la decisión política era adecuada. De este modo se modifica la manera de pensar y se cambian los valores, desembocando en la sustitución de la cultura de que somos herederos por otra distinta que emplea una terminología en ocasiones distinta pero, en otras, semejante, solo que con unos significados nuevos cambiados que deforman y sustituyen a los anteriores.

\section{4) LA RELEVANCIA DE LAS OBJECIONES DE CONCIENCIA}

\section{(4.1) SU CRECIENTE FRECUENCIA}

Presentado el complejo sistema de relaciones jurídicas, éticas y religiosas de la sociedad actual, así como la conexión que en ocasiones se produce entre Derecho y poder político, no puede extrańarnos que el número de circunstancias en que es susceptible de oponerse una objeción de conciencia sea cada vez mayor. Frente a la tradicional al servicio militar, aparecen otras nuevas como son la objeción de conciencia fiscal, laboral, al jurado, las propias del ámbito educativo y, entre otras más que podrían indicarse ${ }^{106}$, se hallan las correspondientes al ámbito sanitario.

104 Lo Castro, G. (1997) 80-94.

105 Lo Castro, G. (1997) 92.

106 Sobre la tipología de objeciones de conciencia, véanse los casos enumerados por: Guarino, A. (1992). Obiezione di coscienza e valori costituzionali. Napoli: Jovene, pp. 63 y ss.; NAVARro Valls, R. (2007). "Las objeciones de conciencia", en Ferrer Ortiz, J. (Coord.): Derecho eclesiástico del Estado Español, 6a ed., Pamplona: EUNSA, pp. 143-176; Navarro Valls, R. I Martínez Torrón, J. (1997). Palomino, R. (2007). "Nuevos supuestos y formas de objeción de conciencia en los Estados Unidos de Norteamérica". RGDCEE, $\mathrm{N}^{\circ} 15$, octubre; TURCHI, V. (2007): "Nuevas formas de objeción de conciencia". RGDCEE, $\mathrm{N}^{\circ} 15$, octubre. 
Los motivos por los que se ha producido esta multiplicación de objeciones de conciencia han sido debidamente analizados por la doctrina. En opinión de Navarro Valls y Martínez Torrón ${ }^{107}$, se debe a que en determinados ámbitos se difunde la opinión de que estamos ante una crisis del positivismo legalista que favorece la consideración de que el ideal de justicia abarca más aspectos que los contenidos en las normas jurídicas. En efecto, como indica en esta ocasión Lo Castro, el fenómeno jurídico no consiste solo en la norma, sino en la entera experiencia jurídica compuesta por otros elementos como la praxis de los tribunales o el amplio tejido de relaciones intersubjetivas de que se compone la vida humana que, en definitiva, son muestras del modo en que una sociedad ha entendido y vivido la dimensión jurídica de la justicia. Además, las normas positivas no tienen vida por sí mismas, sino que viven en unos sujetos que, en su aplicación, pueden orientarlas y dirigirlas en un sentido u otro. En definitiva, el Derecho no es monopolio del legislador, sino un patrimonio común a todos los hombres ${ }^{108}$.

Otro factor que también ha contribuido a esa crisis del positivismo legalista ha consistido en el cambio sobre el concepto de identidad humana acompañado de la recepción jurídica del criterio de la excepcionalidad. Conviene recordar ${ }^{109}$, con el fin de entender esta propuesta, que el planteamiento "moderno" y racionalista del Derecho entendía que la ley podía regular toda situación vital porque también había un modelo común de hombre y de situaciones. Sin embargo, desde que se acepta que no existe ya aquella identidad de contenido de la naturaleza humana tampoco se puede sostener aquel concepto de ley. A ello se ańade que, de modo paralelo a este proceso, desaparece otro de los supuestos de la ley cual es

107 Martínez Torrón, J. (1997). "La ley española al jurado y la objeción de conciencia de clérigos y religiosos". IC, XXXVII; Martínez Torrón, J. / Navarro Valls, R. (2006). "Protecting conscientious objection as a fundamental right. Considerations on the draft agreements of the Slovak Republic with the Catholic Church and with orher registered Churches". RGDCEE, No 12, octubre, pp. 15-17; Navarro Val.ls, R. (2007) 143-145; Navarro Valls, R. / Martínez Torrón, J. (1988) 2-8; Navarro Valls, R. / Martínez TORRÓN, J. (1997) 9-15.

Lo Castro, G. (1997), anticipando este planteamiento en las pp. 4 y ss., y pp. 13-15. En relación con la conveniencia de recuperar el sentido de unidad del ordenamiento jurídico me remito a Ferrer Ortiz, J. (1989). "Los principios constitucionales de Derecho eclesiástico como sistema", en AA. Vv.: Las relaciones entre la Iglesia y el Estado: estudios en memoria del profesor Pedro Lombardía. Madrid: Universidad Complutense de Madrid-Editoriales de Derecho Reunidas, Pamplona: Universidad de Navarra. Pamplona, p. 317; Lombardía, P. (1991). "El concepto actual del Derecho eclesiástico y su marco constitucional", en él mismo: Escritos de Derecho canónico y de Derecho eclesidstico del Estado, vol. 5, Pamplona: EUNSA, pp. 346 y 349; Navarro Valls, R. (1985). "La enseñanza del Derecho canónico en la jurisprudencia española". $A D E E$, I, p. 84; RocA, M. J. "El Derecho canónico como disciplina jurídica básica: implicaciones para su docencia e investigación en las Facultades de Derecho". RGDCEE, $\mathrm{N}^{\circ} 7$, enero, pp. 6 y ss. 
que esta reposa sobre la repetición de unos actos que son, si no idénticos, sí similares. No todos los actos de los hombres gozarán de estas características porque la fragmentación social, o las variaciones en el comportamiento individual, propician la diferencia de las conductas. La ley pierde, de este modo, su capacidad de predeterminar. Se lo impide el constante cambio de situaciones y, por consiguiente, de las decisiones a tomar ante ellas, pues no son ya reductibles a una misma norma ${ }^{110}$.

En este planteamiento es decisiva la entrada de un nuevo término como es la "excepción" que empieza a considerarse desde principios del siglo XX no como algo anómalo o extravagante, "sino como algo unido a toda existencia" 111 . Como indica García-PELAYO ${ }^{112}$, el resultado de esta situación se traduce en que "hay una tendencia a considerar como imposible la predeterminación de las situaciones y, por consiguiente, de las reglas a ellas aplicables; a entender que la rigidez y estabilidad de la ley lleva consigo la imposibilidad de regular eficazmente el dinamismo inherente a la vida social, y que, por tanto, tal regulación se ha de abandonar a decisiones variables, tomadas en función de las circunstancias y situaciones. El intelectualismo que suponía la concepción clásica de la ley ha de ceder el paso a un voluntarismo más o menos condicionado por unos datos reales". Este proceso será, presumiblemente, más acuciante a medida que la sociedad se hace más compleja por la concurrencia de otros factores como son los avances tecnológicos, o el actual proceso migratorio, por poner dos ejemplos.

Ante esta situación, la ley no puede continuar pretendiendo ser en sí misma el "orden social" ni el único elemento vertebrador de la sociedad. Se presentará como expresión parcial del conjunto de la realidad social subyacente. Cada vez es más frecuente la constatación de que cada grupo o cada institución tienen un modo de existir y una estructura que le es inherente. Solo una de las partes de esa estructura es la jurídica ${ }^{113}$. Por ello no puede extrańarnos que se reivindique la legitimidad de conductas que no aparecen previstas en la ley o que, incluso, son contrarias a ellas. Este resultado se producirá siempre que la norma jurídica estime que agota todo el Derecho, que puede configurar toda la regulación de la materia, y que desconoce la creciente complejidad social y variedad de conductas humanas informadas por motivos distintos de los que algunos de ellos están revestidos de exigencias axiológicas.

A estos datos que explican la creciente frecuencia de la invocación

110 García-Pelayo, M. (1999) 73.

111 García-Pelayo, M. (1999) 73. Este concepto trasciende incluso a la teoría general del Estado especialmente a través de Carl Schmitt, sobre todo en su obra Teología politica, tal como estudia el autor español aquí citado.

112 García-Pelayo, M. (1999) 75.

113 García-Pelayo, M. (1999) 75. 
de las objeciones de conciencia se une el valor de las motivaciones que subyacen en los comportamientos de objeción a la ley, distintas de las que desembocan en la simple trasgresión de la norma fundada en el egoísmo. Se ańade el origen mismo de la objeción de conciencia. Ya no se trata solo de imperativos de conciencia derivados de creencias religiosas frente al mandato del poder, sino que se admite que tenga causa en contenidos éticos de conciencia no necesariamente religiosos, sino de creencias con una similar intensidad axiológica. Contemplado en estos términos, observamos que acontece una "secularización" de la objeción de conciencia114.

Como otro de los factores que, precisamente por incidir en la ampliación del grado de heterogeneidad social, contribuye al aumento de probabilidades de presentación de objeciones de conciencia encontramos, en un amplio número de países, el fenómeno migratorio. Su incidencia se ha dejado sentir especialmente en algunos ámbitos concretos como es el sanitario. Así lo ha advertido el Comitato Nazionale per la Bioetica de Italia ${ }^{115}$. La confrontación de culturas distintas que se produce en aquellos casos en que las personas de reciente llegada provienen de lugares culturalmente alejados del país receptor. De esta situación surgirán algunos problemas como son aclarar si los inmigrantes tienen derecho a la asistencia sanitaria pública, si se les puede someter a tratamientos o inspecciones sanitarias obligatorias, y determinar cuáles han de ser los principios que presidan la actividad de los profesionales sanitarios en relación con estos individuos con raíces culturales heterogéneas ${ }^{116}$.

Según el mencionado Comité, la respuesta a estos problemas parte de la consideración de tres principios. Uno de ellos es el terapéutico, que consiste en la obligación de curar a cualquier persona enferma. El segundo es el principio de solidaridad que requiere que se preste atención sanitaria también a los más débiles y necesitados. Finalmente, invoca el principio del respeto a la dignidad de toda persona y de su especificidad cultural, siempre que esas peculiaridades no contrasten con los principios que sustentan el orden jurídico y social ${ }^{117}$. De la aplicación de este principio pueden surgir conflictos deontológicos o de conciencia para el personal especializado que atiende a esa persona que, por sus características culturales o religiosas, solicite un tipo de atención no siempre aceptable ${ }^{118}$.

114 Navarro Valls, R. (2007) 143-145; Navarro Valls, R. / Martínez Torrón, J. (1997) pp. 2-8; Navarro Valls, R. I Martínez Torrón, J. (1988) 9-15.

115 CNB: Problemi bioetici in una società multietnica, de 16 de enero de 1998. Sobre estas cuestiones, Dalla Torre, G. (1993) 16 y ss.; Turchi, V. (2007). "Nuevas formas de objeción de conciencia". Revista General de Derecho Canónico y Eclasiástico del Estado, vol. 15, pp. 1-32. Disponible en línea en: http://www.iustel.com, pp. 21-23.

116 TURCHI, V. (2007) 15.

117 CNB: Problemi bioetici in una società multietnica, de 16 de enero de 1998.

118 En este sentido el Comité italiano entiende que el personal de sanidad no deberá atender ninguna solicitud dirigida a producir lesiones o mutilaciones con finalidades no terapéu- 
Continuando dentro del contexto bioético, es interesante observar el intento de acomodación de la relación entre médicos y pacientes a la nueva situación multicultural. El Comité Consultatif de Bioéthique de Bélgica ha fijado su atención en la falta de comprensión que en ocasiones se produce sobre el paciente de tradición cultural distinta a la información que le ofrece el médico, y no solo en el aspecto lingüístico, sino de mentalidad. Con el fin de superar estas dificultades sugiere que, en la medida de lo posible, se acuda en este tipo de ocasiones a un médiateur culturel capaz no solo de traducir la información proporcionada, sino también de adaptarla a las particularidades propias de la cultura de origen del paciente ${ }^{119}$.

Encontramos finalmente que las objeciones de conciencia emergen de forma paralela a la extensión de la protección jurídica a otros bienes que hasta ahora habían pasado inadvertidos para el universo jurídico. Un ejemplo de estos casos es la progresiva valoración de los animales y la creciente sensibilización social que existe hacia ellos. Esta estimación ha provocado la concesión de una mayor protección que, en lo que aquí afecta, ha desembocado en la posibilidad ofrecida a los científicos de negarse a participar en aquellas investigaciones que exijan la experimentación sobre animales. Este es el caso de la ley italiana $413 / 1993^{120}$. Su artículo primero reconoce expresamente que los ciudadanos que, en el ejercicio de la libertad de pensamiento, conciencia y religión, se oponen a la violencia sobre todos los seres vivos, pueden declarar la propia objeción a cada acto relacionado con la experimentación animal. Como indica el artículo cuarto, esta conducta no podrá comportar discriminaciones de ningún tipo hacia el objetor.

Como conclusión de los distintos factores que se han ido señalando en las líneas precedentes, no puede resultar del todo extraño que se presenten situaciones que sugieran la presentación de objeciones de conciencia. Esta posibilidad perdurará, o incluso se incrementará, mientras se siga manejando un concepto de ley y de modo de legislar desajustado en relación con la sociedad regulada. Dicho en otros términos, parece perpetuarse el concepto racionalista o "moderno" de ley fundado en unos

ticas, independientemente del origen religioso o cultural que puedan presentar, en CNB: Problemi bioetici in una società multietnica, de 16 de enero de 1998.

119 CCB: Avis n. 35, relatif à l'exception thérapeutique, de 13 de marzo de 2006, $\$$ D.1. El ejemplo que pone consiste en que "ainsi, la mort n'est pas chargée du même poids symbolique dans toutes les cultures".

120 Ley 423/1993, de 12 de octubre, en Gazzetta Ufficiale $\mathrm{N}^{\circ} 244$, de 16 de octubre. Sobre esta cuestión, Arami, M. (2003). Introduzione alla Bioetica. 2a ed., Milano: Giuffrè, pp. $542-$ 552; D'agostino, F. (2003). Bioética. Estudios de Filosofía del Derecho. Madrid: Ediciones Internacionales Universitarias, pp. 187-204; Elizari Basterra, F. J. (1991). Bioética. Madrid: San Pablo, pp. 343-350; Kuhse, H. / Singer, P. (2006). Bioethics. 2a ed. Oxford: Blackwell, pp. 559-577; Lucisano, A. (2000). "I diritti animali", en Chieffi, L. (a cura di): Bioetica e diritti dell'uomo. Torino: Paravia, pp. 291-302; Tábano, F. (2003). I diritti degli animali: nuova legge a tutela degli animali. Milano: FAG. 
presupuestos sociales y humanos que, si bien pudieron ofrecer un adecuado resultado en su día, no son los más oportunos para regir al hombre y a la sociedad actuales. Tanto la crisis de la identidad de las personas y de la sociedad, con la consiguiente extensión de la fragmentación ética, junto con los avances técnicos y la aparición de nuevos problemas éticos, dan lugar a que tengan difícil aplicabilidad algunos de los postulados del sistema normativo tradicional. $\mathrm{Ni}$ se puede regular todo -pues no toda la realidad en que vive el hombre es estructurable jurídicamente-, ni tampoco se puede normar cada cuestión del mismo modo, aunque el sustento de una mayoría parlamentaria pueda ofrecer una justificación formal a esa decisión. Es decir, la falta de una identidad en la sociedad y los propios cambios personales conllevan que no sea posible en todo caso ofrecer una misma solución a un mismo problema.

Ignorar estas situaciones y continuar identificando a la ley con todo el Derecho, y a la solución de la norma como la única posible, es una opción que, actualmente, no se puede plantear sin dificultades. Se trata de aplicar unos criterios que ofrecieron su pleno rendimiento en otro tiempo pero que su aplicabilidad en el momento presente puede desembocar en situaciones forzadas. Tan forzadas como tener que ejercitar de un modo directo, a través de una objeción de conciencia, un derecho fundamental como la libertad de conciencia frente al imperativo de una norma. Sería oportuno que el Derecho se replegara y no invadiera ámbitos que no le son propios, como la conciencia humana. Asimismo, sería acertado que el legislador no ignorase el alcance ético de algunas de las materias que regula y evitase, en la medida de lo posible, compromisos para las conciencias.

\section{(4.2) LA SOLUCIÓN A LOS CONFLICTOS JURÍdicos A TRAVÉS DE LAS OBJECIONES DE CONCIENCIA}

La dificultad de conciliar el Derecho y las distintas opciones éticas o morales adquiere una mayor dificultad y relevancia desde el momento en que nos percatamos de que la producción normativa no cesa de aumentar. Ya se ha examinado que esta situación da lugar a que el Derecho invada espacios dejados anteriormente a la moral. Como efecto de esa mayor relevancia del Derecho se está relegando la conciencia a ámbitos cada vez más personales y menos públicos. Se apela de este modo a las normas jurídicas como fuente de la seguridad que necesita toda conducta humana.

Con independencia de la necesidad que se tenga de recurrir al Derecho positivo para encontrar esta seguridad, sucede que no toda la realidad social es susceptible de recibir con igual comodidad la adecuada regulación. Como estamos observando, a medida que una cuestión presenta un debate ético o moral a su alrededor, más difícil es reglarlo por la amplitud 
de puntos de vista y teorías diversas que en una sociedad como la actual recaen sobre esa materia. Por tanto, resulta difícil alcanzar una regulación que no solo abarque todos los aspectos que precisan de ella, sino que sea aceptada sin mayores reticencias.

La objeción de conciencia se presenta como una posibilidad de conciliar los distintos puntos de vista en conflicto. Ante la dificultad de ofrecer unas respuestas normativas definitivas en cualquier situación, sería prudente que el ordenamiento jurídico fuera receptivo a estas objeciones con el fin de lograr un equilibrio entre los principios de actuación que proponen las normas -como reflejo de la voluntad de la mayoría- y los principios inconciliables de unas minorías que también son titulares de derechos. De este modo se concilian valores en principio opuestos sin tener que sacrificar ninguno, considerando a la ley como una "regla de compatibilidad" en lugar de una "regla de prevalencia"121.

Este es el planteamiento que mejor se corresponde con lo que Bertolino denomina "objeción de conciencia moderna". Esta consiste $e^{122}$ en que, a diferencia de tiempos anteriores en que prevalecía ese enfoque de carácter excepcional fruto del consentimiento, se entiende ahora que una verdadera salvaguardia de la dignidad humana y de los derechos que le son inherentes requiere la consideración de la objeción como una manifestación de la libertad de conciencia que se puede ejercer, dentro de los límites previstos, con carácter ordinario y no excepcional. De ese modo se puede salvaguardar lo que, en palabras del Tribunal Constitucional italiano ${ }^{123}$, podemos denominar la "relazione intima e privilegiata dell'uomo con se stesso" que es la "base spirituale-culturale e il fondamento di valore etico-giuridico" de los derechos inviolables de la persona que, como es sabido, garantizan el respeto a la dignidad humana.

Este planteamiento sería el propio de un ordenamiento jurídico como el actual que se precia de girar en torno a un protagonista que es el "hombre total" con unos valores espirituales y éticos que se erigen en vértice de los valores jurídico-positivos que conforman el sistema de derechos y deberes constitucionales. Por este motivo la persona podría oponer

121 Prisco, S. / Cappuccio, L. (2000). "Obiezione di coscienza e trattamenti sanitari obligatori”, en L. Chieffi (a cura di): Bioetica e diritti dell'uomo, Torino: Paravia, p. 59.

123 Sentencia de la "Corte Costituzionale" 467/1991, de 16 de diciembre, FJ cuarto. De acuerdo con esta afirmación, el Tribunal concluye que, si la esfera íntima de la conciencia es base de los derechos inviolables, el tipo de protección que reciba habrá de ser al menos tan intensa como la de los derechos que fundamenta. Como establecen sus propios términos, "la sfera intima della coscienza individuale debe essere considerata come il riflesso giuridico più profondo dell'idea universale della dignità della persona umana che circonda [i diritti inviolabili]". Este "riflesso giuridico" exige "una tutela equivalente a quella accordata ai diritti [inviolabili], vale a dire una tutela proporzionata alla priorità assoluta e al carattere dondante ad essi riconosciuti nella scala dei valori espressa dalla Costituzione italiana", en Bertolino, R. (1994) 65-67. 
el dictado de su conciencia -cuando sea legítimo- a las normas positivas que impidan la afirmación de esa dignidad ${ }^{124}$. Se sustrae, de este modo, a la conciencia del poder de las reglas exteriores.

La objeción de conciencia es, por otra parte, uno de los sistemas más útiles de solucionar los conflictos que en ocasiones se producen en la fragmentada sociedad actual. En efecto, permite que la ley pase a ser considerada una regla de compatibilidad en lugar de una regla de prevalencia definitiva y de imposición de una sola de las opciones posibles para resolver un determinado problema ${ }^{125}$. Se trata de un mecanismo que facilita la coexistencia y conciliación entre valores que, de otro modo, estarían destinados a enfrentarse en una relación dialéctica.

\section{5) LÍMITES DE LA OBJECIÓN DE CONCIENCIA}

La explicación de las causas de las objeciones de conciencia en la sociedad actual, sus proyecciones hacia el futuro y su posibilidad de resolver conflictos no quiere decir que se hayan de estimar las objeciones de conciencia cada vez que se interpongan. Como manifestación del derecho fundamental de libertad religiosa y de conciencia, están también sometidas a sus límites. De este modo, la problemática no se presenta tanto en "admitir o no admitir un teórico derecho general a la objeción de conciencia, cuanto precisar sus límites" 126 .

La objeción de conciencia no podrá llevarse al extremo de concebirse como un instrumento que garantice en todo caso la superioridad de la conciencia frente a la ley y los valores en que esta se sustenta. Por ello la objeción de conciencia aparece limitada por la necesidad de la existencia de un ordenamiento jurídico de carácter imperativo, y ha de ser considerada en relación con los fines sociales que pretende el precepto trasgredi$\mathrm{do}^{127}$. Como afirma el Tribunal Constitucional español, no se pueden invocar los derechos fundamentales para poner en peligro el ordenamiento objetivo de la comunidad nacional, es decir, el Estado democrático ${ }^{128}$.

Ante este conflicto entre un mandato general y un derecho fundamental, el interés se centra en la búsqueda del necesario equilibrio entre ambos o en encontrar la regla que nos permita identificar qué es lo que ha de prevalecer en cada caso. Dicho de otro modo, se trata de ponderar los intereses que entran en conflicto. La dificultad se halla en que ambos intereses son en sí mismos legítimos. Tal como lo podemos entender en el

Bertolino, R. (1994) 65-67 y 80-82.

Bertolino, R. (1994) 81.

Navarro Valls, R. / Martínez Torrón, J. (1997) 25.

Motilla, A. (1993). "Consideraciones en torno a la objeción de conciencia en el Derecho español”. IC, XXXIII, Nº5, p. 146.

Sentencia de la "Corte Costituzionale" italiana 25/1981, FJ quinto. 
ordenamiento jurídico espańol -lo que es extensible a los que se encuentran dentro de su tradición jurídica- uno de esos intereses proviene del ejercicio de un derecho fundamental, mientras que el otro es expresión de un interés general o del ejercicio de otro derecho igualmente digno de reconocimiento. No solo se trata de la legitimidad en cualquier caso presente, sino de que la Constitución española ordena su máxima satisfacción o garantía, pero sin aclarar cuáles son las circunstancias o condiciones en que unos intereses deben triunfar sobre otros $y$, por tanto, sin indicar cuáles son sus casos de aplicación y las posibles excepciones ${ }^{129}$. Esta carencia es lo que explica que una misma conducta pueda presentarse, en un caso, como legítimo ejercicio de un derecho, y en otras situaciones como una infracción jurídica. Cuando el ejercicio de un derecho queda obstaculizado por la aplicación de su límite no significa que este desplace o excepcione a aquel. Ambos elementos continúan siendo relevantes porque estamos ante un régimen de concurrencia normativa y no de exclusión ${ }^{130}$. Por ello la ponderación de los intereses en conflicto adquirirá connotaciones diferentes en cada caso concreto, sin que sea fácil elaborar una suerte de teoría general sobre su resolución ${ }^{131}$.

Esta ponderación, aparte de su capacidad resolutiva, muestra también que es factible enervar la presunción de legitimidad del legislador democrático. Los deberes que provienen de cuanto se aprueba es cierto que los ampara esa legitimidad democrática y del sistema de mayorías, pero en ocasiones como las que ahora estudiamos deben hacer frente a otras razones que encuentran igualmente su origen en las constituciones actuales y, más concretamente, en su catálogo de derechos ${ }^{132}$. Por tanto, existe una presunción de legitimidad a favor del legislador, pero también la hay en beneficio de quien ejercita un derecho fundamental. Habrá que sopesar los argumentos de ambos para ponderar adecuadamente los intereses en conflicto. Precisamente por ello se pueden exponer algunas pautas o parámetros de actuación que ayuden a sopesar esos bienes y determinar de qué mecanismos podemos valernos para establecer las limitaciones al ejercicio de la libertad de conciencia. No en vano, la libertad religiosa se encuentra limitada por el orden público, tal como establecen el artículo 16.1 de la Constitución ${ }^{133}$ espańola y el artículo 3.1 de la ley orgánica de libertad

129 Prieto Sanchís, L. (2007) 33.

130 Tal como indica la STC 254/1988, seguida por la STC 20/1990. Sobre ello me remito a Prieto Sanchís, L. (2007) 34.

131 Consúltese nota a pie de página n. 168.

132 Prieto Sanchís, L. (2007) 39 y ss.; Prieto Sanchís, L. (2006). "Libertad y objeción de conciencia". Persona y Derecho, $\mathrm{N}^{\circ}$ 54, pp. 269 y ss.

133 "Se garantiza la libertad ideológica, religiosa y de culto de los individuos y de las comunidades sin más limitación, en sus manifestaciones, que la necesaria para el mantenimiento del orden público protegido por la ley". 
religiosa ${ }^{134}$ del mismo país. Esta última disposición aclara que este límite consiste en el derecho de los demás al ejercicio de las libertades públicas y derechos fundamentales ${ }^{135}$, así como la salvaguardia de un orden público que se desglosa en la seguridad, la salud y la moralidad pública ${ }^{136}$.

Es conveniente que cuanto se refiere a esta cuestión se contemple desde el prisma más amplio de los límites generales a los derechos fundamentales ${ }^{137}$. En el derecho que tratamos, esta afirmación adquiere una particular relevancia porque su contenido puede ser tan amplio y variado como pueden ser los diferentes mandatos de la conciencia. Ante esta realidad, en lugar de preguntarnos qué conductas -insistimos, imposibles de cuantificar a priori- se pueden realizar, se ajusta mejor a las características de este derecho fundamental intentar descubrir qué es lo que el individuo no puede hacer, pues es en las situaciones de conflicto donde mejor se aprecia la fuerza del derecho y se delimitan los perfiles y límites de los derechos e intereses que concurren ${ }^{138}$.

De un modo u otro, las restricciones al ejercicio de la objeción de conciencia, como sucede con cualquier otro derecho fundamental, se entiende que habrán de ser proporcionales a la satisfacción de otro interés jurídico constitucionalmente relevante ${ }^{139}$. Es, pues, la medida de propor-

134 Ley orgánica española $5 / 1980$, de libertad religiosa, de 5 de julio. Su artículo 3.1. indica que "el ejercicio de los derechos dimanantes de la libertad religiosa y de culto tiene como único límite la protección del derecho de los demás al ejercicio de sus libertades públicas y derechos fundamentales, así como la salvaguarda de la seguridad, de la salud y de la moralidad pública, elementos constitutivos del orden público protegido por la Ley en el ámbito de una sociedad democrática".

135 En efecto, el ejercicio de la objeción de conciencia no puede transformar a otras personas en objetos o simples instrumentos para la satisfacción del imperativo de conciencia, como indica Gascón Abellán, M. (1990). Obediencia al Derecho y objeción de conciencia. Madrid: Centro de Estudios Políticos y Constitucionales, p. 226.

136 Desde las concepciones más amplias del ejercicio de la libertad de conciencia y más restrictivas hacia sus límites se entiende que estos son aplicables solo cuando el acatamiento de la propia conciencia conlleva un atentado contra los derechos fundamentales de otros. En estos casos, estaríamos ante una extralimitación en el ejercicio del derecho fundamental de libertad de conciencia, en Martínez-Pujalte, A. L. (1999). "Libertad de conciencia y tratamiento médico". Persona y Derecho, $\mathrm{N}^{\circ}$ 41, p. 385.

137 Sobre esta cuestión, Brage Camazano, J. (2004). Los limites de los derechos fundamentales. Madrid: Dykinson; Durán y Lalaguna, P. (1996). Los límites del Derecho. Granada: Comares, especialmente pp. 151 y ss. En relación con la aplicabilidad de la teoría del abuso de derecho a un ejercicio indebido de los derechos fundamentales y los distintos interrogantes que suscita, Serrano, J. L (2006). "La clasificación de los derechos constitucionales y el ejercicio abusivo de derechos fundamentales". Persona y Derecho, $\mathrm{N}^{\circ} 54$, pp. 275 y ss., particularmente pp. 282-291.

138 Prieto Sanchís, L. (2006) 262 y ss.

139 STC 52/1995, FJ quinto. STC 37/1998, FJ quinto. Como afirma el Tribunal Constitucional italiano, "Il legislatore, nel suo discrezionale bilanciamento dei valori costituzionali [può] restringere il contenuto di un diritto inviolabile dell'uomo soltanto nei limiti strettamente necessari alla protezione dell'interesse pubblico sottostante al dovere costituzionale contrapposto", en la sentencia 467/1991, de 16 de diciembre, FJ quinto. 
cionalidad la que determina la constitucionalidad de cualquier medida restrictiva de un derecho fundamental ${ }^{140}$. Como indica el Tribunal Constitucional espańol, "para comprobar si una medida restrictiva de un derecho fundamental supera el juicio de proporcionalidad, es necesario constatar si cumple los tres requisitos o condiciones siguientes: si tal medida es susceptible de conseguir el objetivo propuesto (juicio de idoneidad); si, además, es necesaria, en el sentido de que no exista otra medida más moderada para la consecución de tal propósito con igual eficacia (juicio de necesidad); y, finalmente, si la misma es ponderada o equilibrada, por derivarse de ella más beneficios o ventajas para el interés general que perjuicios sobre otros bienes o valores en conflicto (juicio de proporcionalidad en sentido estricto)" 141 .

Se pueden indicar algunos criterios más concretos que ayuden a resolver los problemas planteados. Por un lado, parte de la doctrina afirma que, cuando el deber se establece en beneficio del propio sujeto, debe prevalecer la libertad de conciencia; pero si el fin es proteger los derechos de otras personas o intereses de convivencia, es la obligación legal la que debe salvaguardarse ${ }^{142}$. En relación con esta observación, es cierto que no todas las obligaciones que nacen del ordenamiento jurídico afectan en igual grado a todos los individuos. Antes bien, algunos ni siquiera se encuentran afectados. Por otra parte, la obligación jurídica habitualmente es fundamental para la satisfacción del bien protegido, pero en otras ocasiones es circunstancial o se puede sustituir fácilmente por otra conducta ${ }^{143}$.

Por otra parte, sería conveniente dilucidar el nivel potencial de peligro social de los comportamientos reclamados por la conciencia ${ }^{144}$. En este sentido, ofrece menor peligro social la pretensión de no cumplir el contenido de una norma jurídica, que el hecho de oponer una actitud activa frente a una norma que prohíbe desarrollar la conducta deseada.

A la hora de permitir el incumplimiento -por motivos de conciencia- del mandato general, también pueden tomarse en consideración

140 STC 37/1998, FJ octavo, remitiéndose a las SSTC 37/1989, 66/1995, 55/1996 y 207/1996.

141 STC 37/1998, FJ octavo. Como afirma la STC 154/2002, FJ séptimo, la respuesta constitucional a los conflictos jurídicos que derivan del ejercicio de los derechos fundamentales concretamente la libertad de creencias y de culto- ha de pasar por un juicio ponderado que atienda a las particularidades del caso. Ese juicio ha de establecer el alcance de un derecho a la vista de la incidencia que su ejercicio pueda tener sobre otros titulares de derechos y bienes constitucionalmente protegidos y sobre los elementos integrantes del orden público protegido por la ley.

142 Motilla, A. (1993) 148.

143 Gascón Abellán, M. (1990) 226 y ss.

144 Navarro Valls, R. / Martínez Torrón, J. (1997) 29; Martínez Torrón, J. (1992). "Las objeciones de conciencia y los intereses generales del ordenamiento", Revista de la Facultad de Derecho de la Universidad Complutense, N 79, p. 203. 
estos dos $\operatorname{argumentos}^{145}$. El primero consiste en que la actividad que el ciudadano está llamado a realizar es colectiva o no individualizada. Con ello identificamos aquellos deberes que se satisfacen mediante un conjunto complejo de acciones ejecutadas por varios sujetos, como sucede con la defensa nacional. En segundo lugar, encontramos que resulta más admisible la objeción a un deber cuando su cumplimiento se atribuye a colectivos en los que no es necesario que todos sus miembros actúen. Basta con que alguno de los componentes del grupo realice esa acción, independientemente de su identificación personal. De este modo, la persona llamada inicialmente a actuar puede ser sustituida fácilmente por otra. A través de esta medida se asegura la continuidad del servicio prestado, y el beneficio que se reporta a quien es destinatario de esa acción no queda interrumpido ni cercenado. Es cuanto le sucede al personal sanitario que, en principio, debe aplicar u omitir -según los casos- un tratamiento y se niega por motivos de conciencia, pero resultando factible, al mismo tiempo, su sustitución por un compañero.

Otro criterio consiste en otorgar un mayor grado de tutela a las objeciones basadas en motivos religiosos que en los simplemente ideológicos, como muestra la mayor parte de los ejemplos del Derecho comparado. La base de esta afirmación se encuentra en que los últimos motivos indicados -los ideológicos- presentan un carácter eminentemente personal, lo que a juicio de los poderes públicos puede presentar un mayor riesgo de fragmentación de las instancias sociales. A ello se une que las creencias religiosas son comunes al resto de correligionarios, lo que le confiere al individuo las garantías que le corresponden al grupo ${ }^{146}$.

Estos criterios, tal como se han enunciado, no son conformes con el contenido de la sentencia 161/1987 del Tribunal Constitucional espańol. En este texto, el mencionado Tribunal sostiene que el incumplimiento de las normas como consecuencia de la objeción de conciencia no está reconocido por el Derecho puesto que ello significaría la negación misma de la idea de Estado ${ }^{147}$. Por tanto, desde este punto de vista no parece posible que se pueda aplicar la objeción de conciencia salvo que así esté expresamente previsto en una norma jurídica.

El Tribunal Supremo ${ }^{148}$ español, sin embargo, ha tenido ocasión de calificar la oposición de la objeción de conciencia como un derecho

Indicados por Ruiz Miguel, A. (1996) 13 y ss.

Navarro Valls, R. I Martínez Torrón, J. (1997) 30 y ss. Es contrario a este criterio Souto PAz, J. A, en su obra Comunidad politica y libertad de creencias, donde afirma, en la p. 327, que "la fuerza de la obligación ética de la conciencia tiene su origen en el individuo mismo [...] Por eso, no debe atribuirse mayor valor a la actuación en conciencia, que trae su causa de una norma religiosa, pues lo relevante es el carácter imperativo de esa convicción personalísima, que se ha fraguado en la propia conciencia".

STC 161/1987, FJ tercero.

STS, Sala Tercera, de 28 de junio de 1999, FJ segundo. 
subjetivo, y ha entendido que existe una acción de garantía del derecho de libertad ideológica y de conciencia para los afectados ${ }^{149}$. Sin embargo, de un modo cercano a cuanto ha expuesto el Tribunal Constitucional, no parece que se pueda sostener que sea una afirmación de carácter general, sino que lo será cuando así venga reconocido expresamente por la ley, como sucedía en el caso de la posibilidad de objetar a la prestación del servicio militar ${ }^{150}$.

También dentro de la doctrina hay quien entiende que toda objeción de conciencia ha de encontrarse expresamente reconocida por las leyes para que pueda permitirse. Este constituiría el mejor modo de asegurar su reconocimiento en relación con ciertas obligaciones legales y que se someta a sus correspondientes límites ${ }^{151}$. La piedra clave de la argumentación descansa en que todo comportamiento humano, incluidos los originados en lo más íntimo de la persona, dotados de una alta carga axiológica, y aun cuando se considere que la objeción es un derecho constitucional, tienen como límites los demás derechos y los valores del ordenamiento. Lo contrario significaría que los comportamientos originados por cualquier creencia, por aberrantes que fueran, deberían estar permitidos. Esto no sería sino el fin del Estado de Derecho e incluso de la existencia de cualquier orden jurídico que arbitre la convivencia ${ }^{152}$.

Una tesis que concilie la salvaguardia de la conciencia con la necesidad de que las leyes no se incumplan arbitrariamente puede consistir en que "solo son supuestos de objeción de conciencia los casos de oposición al cumplimiento de un deber jurídico porque resulta contrario a las propias convicciones morales, y no a otro tipo de convicciones, es decir, porque el deber jurídico resulta contrario a un deber moral" ${ }^{153}$. Si

149 STS de 23 de abril de 2005, Sala Tercera, FJ quinto, refiriéndose concretamente a la acción de garantía de ese derecho que corresponde a los profesionales sanitarios con competencias en materia de prescripción y dispensación de medicamentos.

150 Ley española 48/1984, de 26 de diciembre, modificada por la ley orgánica 8/1984 también de 26 de diciembre, sobre el régimen de recursos y régimen penal. El contenido de la ley 48/1984 lo desarrolló el real decreto 266/1995, de 24 de febrero, sobre objeción de conciencia y prestación social sustitutoria. Este era asimismo el contenido de la orden ministerial de 29 de diciembre de 1989 , sobre asistencia sanitaria a objetores de conciencia. También se refería al régimen de la objeción de conciencia al servicio militar la ley orgánica 13/1991, de 20 de diciembre, y el real decreto 525/1992, de 22 de mayo. Aluden a la necesidad de una ley que reconozca el derecho de objetar para que este puede ejercitar las sentencias de la Sala Segunda del Tribunal Supremo español 637/1997, de 18 de noviembre, y 746/1999, de 11 de mayo, FJ tercero en cada caso.

151 Motilla, A. (1993) 144 y 148.

152 Motilla, A. (1993) 144.

153 Martínez-Pujalte, A. L. (1999) 386. En este sentido, Martínez Torrón, J. (1992) 202. Cuando la persona prefiere optar por seguir los dictados de su conciencia contra la ley, lo decide por medio de un mecanismo axiológico distinto del puramente psicológico de quien la trasgrede egoístamente con el fin de conseguir un beneficio propio, según D'Agostino, F. (1989). "Obiezione di coscienza e verità del Diritto tra moderno e postmoderno". $Q D P E, \mathrm{~N}^{\circ} 2$, pp. 3 y ss.; D'Agostino, F. (1993). "L'obiezione di coscienza nelle dinamiche 
la libertad de conciencia deriva de las libertades ideológica y de culto, se entiende que ese deber moral aducido ha de fundarse en una ideología o en una religión ${ }^{154}$. El mismo Tribunal Europeo de Derechos Humanos ha distinguido las convicciones y creencias que provienen de un sistema de pensamiento suficientemente estructurado, coherente y sincero, de las simples opiniones o ideas ${ }^{155}$. El Tribunal Supremo español también se ha mostrado exigente en este extremo. Ha considerado que referencias a simples conceptos como el antimilitarismo, sin mayores explicaciones, no son suficientes para atender una objeción de conciencia. Han de constituir motivos que expresen convicciones de orden religioso, ético, moral, humanitario, filosófico u otro de la misma naturaleza ${ }^{156}$.

Tal como aparece interpretado el ejercicio de la objeción de conciencia por los tribunales españoles, no es aventurado concluir que el derecho de libertad de conciencia no se encuentra debidamente garantizado. Sustentan esta apreciación datos como la afirmación jurisprudencial, anteriormente señalada, consistente en que la libertad de conciencia tan solo se permite en las situaciones en que expresamente lo reconoce una ley. Es cierto que esto ofrecería una mayor seguridad jurídica pero, a su vez, esta pretendida necesidad de reconocimiento legal entrańa determinadas dificultades de ejercicio. Analicemos a continuación estas cuestiones.

\section{6) POSIBILIDAD DE REGULAR LAS OBJECIONES DE CONCIENCIA}

No se debe desconocer que la objeción de conciencia es, por su propia definición, un fenómeno esencialmente individual. Afecta, como ha indicado parte de la doctrina, no tanto al hombre abstractamente consi-

postmoderne", en Guitarte Izquierdo, V. / Escrivá Ivars, J. (eds.): La objeción de conciencia. Actas del VI congreso internacional de Derecho eclesiástico del Estado. Valencia: Consejo General del Poder Judicial-Generalitat Valenciana, pp. 23 y ss. Martínez-Pujalte, A. L. (1999) 386.

155 STEDH: Campbell and Cosans de 25 de febrero de 1982, $\$ \$ 36$ y 37 . Han estudiado esta cuestión Ergec, R. (1992). "L'objection de coscience en Droit Européen", en AA. Vv.: Conscientious Objection in the E. C. Countries-Proceedings of the Meeting. Milano: Giuffrè, pp. 5-11; Martínez Torrón, J. (1993). "La giurisprudenza degli organi di Strasburgo sulla libertà religiosa”. Rivista Internazionale dei Diritti dell'Uomo, pp. 344 y ss.; Martí, J. M. (1999). "La objeción de conciencia: visión de conjunto". $A D E E$, p. 46 y ss.

STS, Sala Tercera, de 28 de febrero de 1997, FJ tercero. Esta es la idea que transmiten las sentencias de la Sala Segunda del Tribunal Supremo n. 637/1997, de 18 de noviembre, y 746/1999, de 11 de mayo, FJ tercero en ambas. El criterio referido a la necesidad de invocar motivos serios lo comparte el Consejo de Estado italiano. El reconocimiento del status de objetor de conciencia al servicio militar no puede basarse únicamente en un genérico repudio al uso de las armas o de la fuerza. Hace falta un quid pluris consistente en la íntima convicción de conciencia, religión o pensamiento tan intenso como para no poder ser violada sino a precio de un verdadero "trauma psicológico", según la sentencia de la "Corte Costituzionale" italiana 467/1991, de 16 de diciembre, FJ tercero, y la sentencia del Consejo de Estado, sección VI, de 22 de marzo de 2007, n. 1360. Disponible en línea en: www.olir.it 
derado, como al hombre "en situación", es decir, contemplado tal como es en sí mismo, y dentro de un sistema jurídico y de la sociedad ${ }^{157}$. Es la conciencia de cada persona la que se encuentra en conflicto con la norma legal. Esta situación provoca que sea particularmente difícil su regulación legislativa. En efecto, no se puede pensar "que sea únicamente el temor a producir un "cataclismo" lo que se encuentra tras la decisión de no legislar en materia de objeción de conciencia, sino la extraordinaria dificultad que ello conlleva"158. De hecho, cuando se reconoce por medio de una norma jurídica una objeción de conciencia, la solución legal pretende más bien resolver un problema de conciencia social, que es contraria a ese deber legal, que un problema de conciencia individual, cuya naturaleza individualizadora es incapaz de captar y regular la norma general ${ }^{159}$.

Hay otras causas que dificultan la oportunidad de ofrecer una solución genérica a los distintos supuestos en que se podría oponer la objeción de conciencia. Existe una amplia cantidad de hipótesis en que es posible presentar una situación de objeción de conciencia, por lo que no se pueden prever todas ellas a prior ${ }^{160}$. En el ámbito en que nos movemos pocas son las respuestas definitivas que pueden darse en este sentido $^{161}$. Esto es lo que impide que la legislación cumpla con una plena satisfacción la regulación de las distintas objeciones oponibles. Además, el reconocimiento legal de la objeción requiere un estudio previo del posible impacto de las consecuencias legislativas que, en ocasiones, es más bien imprevisible ${ }^{162}$. El único caso en que esta podría adquirir una mayor eficacia sería aquel en que la objeción haya adquirido una cierta extensión social $^{163}$.

Bertolino, R. (1994) 14.

Ibán, I. C., en el prólogo a Cebriá García, M. (2005). Objeciones de conciencia a intervenciones médicas. Pamplona: Thomson-Aranzadi, p. 15.

Souto Paz, J. A (2003) 327.

I.C. Ibán, en el prólogo a Cebriá García, M. (2005) 15.

Navarro Valls, R. I Martínez Torrón, J. (1997) 29; Navarro-Valls, R. / MartínezTorrón, J. / Jusdado, M. A (1988). "La objeción de conciencia a los tratamientos médicos: Derecho comparado y Derecho espańol". Persona y Derecho, N 18, p. 264. Lo mismo sucede en otros aspectos de la realidad donde los elementos espirituales del hombre adquieren un particular protagonismo. Es, por ejemplo, el caso de la presencia de símbolos religiosos en los lugares públicos como las escuelas o los hospitales. Atendiendo a los conflictos que se originan, donde se ven afectadas las creencias de cada uno de los que allí se encuentran presentes, lo más oportuno es que se resuelva la cuestión debatida en ese momento, en ese lugar, y por las personas afectadas, sin que sea conveniente la adopción de una decisión general a través de una norma jurídica que, con toda probabilidad, lejos de resolver los problemas creará otros nuevos y lesionará forzosamente la conciencia de parte de los destinatarios. Esta cuestión ha sido tratada con mayor profundidad en González-VARAs Ibáñez, A. (2006). "La simbología religiosa en los espacios públicos: problemas generales y soluciones concretas en los Estados europeos", en Iglesias caniche, I. C. (Dir.): Inmigración y Derecho. Valencia: Tirant lo Blanch, pp. 249-296.

Palomino, R. (2007) 51

Martínez Torrón, J. (2005) 4. 
Por otra parte, la legislación suele aprobarse con tardanza, es decir, cuando ya se han presentado varios casos de objeción no previstos y, en ocasiones, con la correspondiente lesión de la conciencia. A ello se añade el dato consistente en que, en numerosas ocasiones, los jueces del contexto jurídico continental europeo y de los países de la misma tradición, son reticentes a aplicar la directamente la Constitución o de las declaraciones internacionales de derechos humanos ${ }^{164}$.

Estas dificultades se presentan a pesar de que no parece discutible que su previsión legal presente ventajas. La fundamental de ellas es la seguridad que proporciona al objetor conocer con certeza cuál es el supuesto que se reconoce. En unos sistemas jurídicos como los nuestros en que, a diferencia de cuanto acontece en los sistemas de Commom Law, se tiende a considerar que todo el Derecho está en la ley y que esta es la única que representa los intereses generales ${ }^{165}$, es útil que las objeciones de conciencia se reconozcan por vía legislativa ${ }^{166}$.

En definitiva, legislar se convierte en una actividad conveniente en un contexto donde continúa prevaleciendo la "perspectiva legalista" sobre el "equilibrio de intereses"167. Este último sistema consiste en la búsqueda del mayor grado de protección para la libertad sobre la intangibilidad

Martínez Torrón, J. (2005) 8 y ss.; Martínez Torrón, J. (1989) 117 y ss.; Martínez Torrón, J. I Navarro Valls, R. (2006) 15-17. Se muestra también a favor de que se regulen las objeciones de conciencia CAStro Jover, A. (1998). "La libertad de la conciencia y la objeción de la conciencia individual en la jurisprudencia constitucional espańola”, en Martínez Torrón, J.: La libertad religiosa y de conciencia ante la justicia constitucional. Granada: Comares, pp. 133-186; GonzÁlez-Varas IbáÑez, A. (2007). "La objeción de conciencia del farmacéutico en la jurisprudencia y su regulación legal en España”. RGDCEE, $\mathrm{N}^{\circ} 15$, octubre; GonzÁlez Moreno, B. (2007). "Límites éticos y derechos de participación democrática en la regulación de las biotecnologías". RGDCEE, $\mathrm{N}^{\circ} 15$, octubre, p. 20 . En relación con la posibilidad de recoger en textos legales las objeciones de conciencia consúltense las distintas aportaciones recogidas en Roca Fernández, M. J (Coord.) (2007). Opciones de conciencia. Propuestas para una ley. Valencia: Tirant lo Blanch. Véase nota a pie de página n. 168.

166 De esta conveniencia dan testimonio algunos logros alcanzados en el Derecho comparado. En este sentido, el artículo12 de la ley de libertad religiosa de Portugal, n. 16/2001, de 22 de junio, reconoce el derecho a objetar dentro de los límites establecidos por la Constitución y la ley que desarrolle este derecho. Por otra parte, el artículo 7 del acuerdo entre la República eslovaca y la Santa Sede de 24 de noviembre de 2000, prevé la posibilidad de objetar a los católicos, reservando la especificación de los términos a un futuro acuerdo. Este texto llegó a elaborarse en el ańo 2005. Sin embargo, esta norma pacticia recibió la desaprobación del "European Union Network of Independent Experts on Fundamental Rights" a través de su Opinión n. 4-2005 de 14 de diciembre. El motivo en que justifica su pronunciamiento son los posibles problemas que podría crear este acuerdo para la salvaguardia de otros derechos fundamentales. Parece ignorar que, con esta apreciación, disminuye la protección de otro derecho fundamental como es el de libertad de conciencia. Sobre estas cuestiones, Martínez Torrón, J. / Navarro Valls, R. (2006) 19 y ss. Asimismo, Marchei, N. (2007). "L'accordo tra la Santa Sede e Slovacchia sull'obiezione di coscienza al vaglio del Parlamento Europeo". QDPE, N ${ }^{\circ} 1$, pp. 203-218. 
de la legislación formal. Por ello, la objeción de conciencia no se concibe tanto como una excepción consentida al orden legal establecido, como el ejercicio de un derecho fundamental. Por tanto, su práctica se encuentra libre de desconfianzas. Desde este punto de vista, la objeción de conciencia no se presenta solamente como la defensa que una persona realiza de un interés privado. Trasciende esta situación desde el momento en que esa pretensión tiene su fundamento en el ejercicio de un derecho fundamental, y la garantía de estos derechos es un verdadero interés público ${ }^{168}$. La consecuencia de este planteamiento es que, en realidad, nos encontramos ante el conflicto de dos intereses públicos.

Mientras no se realice una adecuada recepción legislativa de las objeciones de conciencia, y atendiendo a la particularidad de las situaciones susceptibles de presentarse, lo más oportuno es solucionarlas singularizadamente a medida que aparezcan utilizando los criterios de ponderación de los intereses analizados en el epígrafe anterior. La consecuencia de este planteamiento es el particular realce que adquiere la función de los tribunales. La sede judicial es aquella que más adecuadamente puede ponderar los bienes jurídicos que entran en conflicto cuando el individuo elude el cumplimiento de un deber jurídico por razones de conciencia ${ }^{169}$, sobre todo cuando este último bien guarda una particular sensibilidad. Es presumible ${ }^{170}$ que la solución ofrecida entronque adecuadamente con la conciencia social en el respeto, como no puede ser de otro modo, del principio de legalidad.

\section{CONCLUSIONES}

A lo largo de estas páginas se ha examinado el significado que adquieren las objeciones de conciencia en el actual contexto jurídico y social. Si hasta hace unas décadas se trataba de un instituto que se

168 Martínez Torrón, J. (1992) 212 y ss.; Martínez Torrón, J. (1997) 303.

169 Dalla Torre, G. (1993) 6-8; Martínez Torrón, J. (1992) 209; Martínez Torrón, J. (2005) 9; Martínez Torrón, J. (1989) 106; Navarro Valls, R. / Martínez Torrón, J. (1997) 26 y ss. En este sentido, Martí, J. M. (1999) 50; Ruiz Miguel, A. (1996) 13. Ejemplo de la significación de la jurisprudencia en el reconocimiento de las objeciones de conciencia -o "exenciones a la ley" - lo ofrece Estados Unidos, como ha expuesto con rigor Palomino, R. (1994) 35-47. En este país, la jurisprudencia se ha mostrado apta para aplicar los principios constitucionales a supuestos de objeción de conciencia en que la legislación no tenía previsto nada. La clave de su actuación ha estado en el esfuerzo desempeñado por la judicatura consistente en buscar la solución justa para cada supuesto singular. Han sabido dictaminar cuándo era arriesgado extender la objeción de conciencia hasta límites peligrosos, cuándo la objeción propuesta era auténtica y, en este caso, de qué modo podía llegarse a una conciliación adecuada. Palomino, R. (1994) 51 y ss. En relación con la necesaria ponderación de los intereses en conflicto en torno a una objeción de conciencia remítase el lector a Guarino, A. (1992) 55-61.

170 Falcón y Tella, M. J. (2001). "Libertad ideológica y objeción de conciencia". Persona y Derecho, No 44, p. 198. 
ejercitaba en escasas ocasiones y que se identificaba en todo caso como una conducta antijurídica, en el momento presente su relevancia ha aumentado y puede aventurarse que su alcance será mayor en los tiempos futuros. La propia dinámica de las sociedades, reguladas por los correspondientes ordenamientos jurídicos, avala esta consideración. La disgregación ética, moral y religiosa provoca que cada vez sea más difícil que el contenido de las normas sea aceptado por todos los ciudadanos, especialmente en aquellas materias que afectan a la esfera espiritual del hombre, como son la enseñanza o las cuestiones bioéticas. Esto provocará que quienes sostienen -basándose en motivos religiosos o no religiosos pero con un contenido axiológico de intensidad equiparable-criterios incompatibles con los expuestos por la ley, se nieguen a cumplirlos. Las reacciones serán mayores en aquellos casos en que los poderes públicos adoptan decisiones que son contrarias al sentir general de la población. Esto puede suceder cuando la norma no es colmada con los valores que esa sociedad ha compartido tradicionalmente, sino que el legislador se sirve de ella para establecer otros modos de proceder, corriéndose el riesgo incluso de transformar la mentalidad social habida cuenta del poder educador que toda norma tiene por el hecho de ser aprobada mediante el procedimiento legítimo.

Si entendemos que la objeción de conciencia es una manifestación del derecho fundamental de libertad religiosa y de conciencia, sucede, en último término, que en cada objeción se contraponen dos intereses legítimos. Por una parte, el interés particular proveniente del ejercicio individual del derecho fundamental mencionado y, por otro lado, el interés general representado por la norma. No es fácil ofrecer solución al conflicto que surge. Es cierto que podrían evitarse estas situaciones si se regularan los casos en que es posible objetar, especialmente en sistemas jurídicos como los europeos continentales y de los países que participan de esta tradición, donde la práctica jurídica demuestra que no siempre es fácil aceptar contenidos del Derecho que no estén expresamente previstos en la norma positiva. Independientemente de que, en caso de regularse, es probable que ya no estuviéramos tanto ante una objeción de conciencia propiamente dicha como ante una opción permitida por la ley, sucede que es difícil prever todos los casos en que puede haber un conflicto para la conciencia.

Ante esta situación, se muestra más aconsejable ponderar los intereses que entran en conflicto en cada caso y examinar cuál de ellos merece prevalecer sobre el otro. Es conveniente que sea el órgano jurisdiccional competente el que realice este prudente examen, pues es se encuentra más cercano al caso.

Por tanto, la objeción de conciencia, si se ejercita dentro de sus límites y por ello no lesiona el orden público ni los derechos de terceros, puede llegar a prosperar. Con ello, la norma sigue vigente y al mismo tiempo 
se salva la lesión a la libertad de conciencia de un ciudadano. Teniendo en cuenta la creciente heterogeneidad que presenta la sociedad, reconocer la pretensión del objetor cuando esta es legítima, puede ser una de las posibles soluciones ante los desajustes entre el contenido de la norma y la conciencia individual.

\section{BIBLIOGRAFÍA}

- Arami, Michele (2003). Introduzione alla Bioetica. 2a ed. Milano: Giuffrè.

- Ballesteros, Jesús (2000). "Postmodernidad y tercer milenio". Persona y Derecho, vol. 43, pp. 15-31.

- Bertolino, Rinaldo (1994). L'obiezione di coscienza "moderna". Per una fondazione costituzionale del diritto di obiezione. Torino: Giappichelli.

- Bettetini, Andrea (2003). "Sobre las relaciones entre religión, Derecho canónico y Derecho político en la sociedad posmoderna", $R e$ vista General de Derecho Canónico y Eclesiástico del Estado, vol. 3, pp. 1-23. Disponible en http://www.iustel.com

- Brage Camazano, Joaquín (2004). Los límites de los derechos fundamentales. Madrid: Dykinson.

- Castro Jover, Adoración (1998). "La libertad de la conciencia y la objeción de la conciencia individual en la jurisprudencia constitucional espańola”. En Martínez Torrón, Javier. La libertad religiosa y de conciencia ante la justicia constitucional. Granada: Comares, pp. 133186.

- Cebriá García, María Dolores (2005). Objeciones de conciencia a intervenciones médicas. Pamplona: Thomson-Aranzadi.

- Cossio Díaz, José Ramón (1989). Estado social y derechos de prestación. Madrid: Centro de Estudios Constitucionales.

- D’Agostino, Francesco (2003). Bioética. Estudios de Filosofía del Derecho. Madrid: Ediciones Internacionales Universitarias.

- (1991). "Dalla bioetica alla biogiuridica". Persona y Derecho, vol. 24, pp. 9-22.

(2000). "Ética y Derecho entre lo moderno y lo postmoderno". Persona y Derecho, vol. 42, pp. 17-31.

(1989). "Obiezione di coscienza e verità del Diritto tra moderno e postmoderno". Quaderni di Diritto e Politica Ecclesiastica, No 2, pp. 3-14.

(1993). "L'obiezione di coscienza nelle dinamiche postmoderne". En Guitarte Izquierdo, Vidal; Escrivá Ivars, Javier (editores). La objeción de conciencia. Actas del VI Congreso internacional de Derecho eclesiástico del Estado. Valencia: Consejo General del Poder Judicial-Generalitat Valenciana. 
(1987). "Il problema della bioetica in una società pluralistica". En AA. VV. Atti dell'88 Congresso della Società italiana di medicina interna. Roma: Pozzi, pp. 8-15.

- Dalla Torre, Giuseppe (1993). Bioetica e Diritto. Saggi. Torino: Giapicchelli.

- De Fuenmayor, Amadeo (2003). La inspiración cristiana de las leyes. Pamplona: Instituto Martín de Azpilcueta.

- Durán y Lalaguna, Paloma (1996). Los límites del Derecho. Granada: Comares.

- Elizari Basterra, Francisco Javier (1991). Bioética. Madrid: San Pablo.

- Ergec, Rusen (1992). "L'objection de coscience en Droit Européen". En AA. VV. Conscientious Objection in the E. C. Countries-Proceedings of the Meeting. Milano: Giuffrè, pp. 5-11.

- Escobar Roca, Guillermo (1993). La objeción de conciencia en la Constitución española. Madrid: Centro de Estudios Constitucionales.

- Falcón y Tella, María José (2001). "Libertad ideológica y objeción de conciencia". Persona y Derecho, vol. 44, pp. 173-217.

- Fernández Segado, Francisco (1986). "El derecho a la vida en la Jurisprudencia constitucional". Revista de Legislación y Jurisprudencia, vol. 6, pp. 801-869.

(2003). "La dignidad de la persona como valor supremo del ordenamiento jurídico espańol y como fuente de todos los derechos". Jus, No 2, pp. 201-233.

- Ferrer Ortiz, Javier (1989). "Los principios constitucionales de Derecho eclesiástico como sistema". En AA. VV.: Las relaciones entre la Iglesia y el Estado: estudios en memoria del profesor Pedro Lombardía. Pamplona: Universidad Complutense de Madrid-Editoriales de Derecho Reunidas-Universidad de Navarra, pp. 309-322.

- Forsthoff, Ernst (1986). "Concepto y esencia del Estado social de Derecho”. En AA. VV. El Estado social. Madrid: Centro de Estudios Constitucionales.

- (1986). "Problemas constitucionales del Estado social". En AA. VV. El Estado social. Madrid: Centro de Estudios Constitucionales.

drid: ENAP.

(1967). Sociedad industrial y Administración pública. Ma-

- Gabaldón López, Jesús (2001). "Libre desarrollo de la personalidad y derecho a la vida". Persona y Derecho, vol. 44, pp. 133-172.

- Gallego Anabitarte, Alfredo (1992). "Derechos fundamentales y garantías institucionales: una recepción jurídico doctrinal", estudio preliminar a la obra de Díaz Lema, José Manuel. Los conciertos educativos en el contexto de nuestro Derecho nacional, y en el Derecho comparado. Madrid: Marcial-Pons. Madrid, pp. 7-42. 
- García-Pelayo, Manuel (1999). Derecho constitucional comparado. Madrid: Alianza Editorial.

- Gascón Abellán, Marina (1990). Obediencia al Derecho y objeción de conciencia. Madrid: Centro de Estudios Constitucionales.

- González-Varas Ibáñez, Alejandro (2007). Consejo y consentimiento en los órganos colegiados canónicos. Su incidencia en el Derecho Público secular medieval. Valencia: Tirant lo Blanch.

(2007). "La objeción de conciencia del farmacéutico en la jurisprudencia y su regulación legal en España". Revista General de Derecho Canónico y Eclesiástico del Estado, vol. 15 (octubre de 2007), pp. 1-18. Disponible en http://www.iustel.com (2008). "La proyección jurídica del pluralismo religioso". Anuario de Derecho Eclesiástico del Estado, vol. XXIV, pp. 387-409. (2006). "La simbología religiosa en los espacios públicos: problemas generales y soluciones concretas en los Estados europeos". En Iglesias Canle, Inés (directora). Inmigración y Derecho. Valencia: Tirant lo Blanch. pp. 249-296

- González Moreno, Beatriz (2005). "Delimitación del objeto del Derecho eclesiástico". Anuario de Derecho Eclesiástico del Estado, vol. XXI, pp. 129-156.

(2007). "Límites éticos y derechos de participación democrática en la regulación de las biotecnologías". Revista General de Derecho Canónico y Eclesiástico del Estado, vol. 15, pp. 1-25. Disponible en http://www.iustel.com

- Guarino, Antonio (1992). Obiezione di coscienza e valori costituzionali. Napoli: Jovene.

- Hervada, Javier (1987). "Bases críticas para la construcción de la ciencia del Derecho eclesiástico del Estado". Anuario de Derecho Eclesiástico del Estado, vol. III, pp. 25-38.

Pamplona: EUNSA.

(1992). Lecciones propedéuticas de Filosofía del Derecho.

(2002). "Libertad religiosa y relativismo", en Hervada, Javier. Los eclesiasticistas ante un espectador. $2^{\text {a }}$ ed. Pamplona: Navarra Gráfica Ediciones, pp. 61 y ss.

- Krajewski, Piotr (2001). "Diritto della morte, diritto alla morte". Apollinaris, vol. 74, No 1-4, pp. 163-205.

- Kuhse, Helga; Singer, Peter (2006). Bioethics. 2a ed. Oxford: Blackwell.

- Lois Cabello, María Concepción (1987). "Conciencia". En AA. VA. Gran Enciclopedia Rialp. Madrid: Rialp, tomo VI, pp. 174 y s.

- Lombardía, Pedro (1991). "El concepto actual del Derecho eclesiástico y su marco constitucional". En Lombardía, Pedro. Escritos de Derecho canónico y de Derecho eclesiástico del Estado, vol. V. Pamplona: EUNSA, pp. 315-408. 
- Lucisano, Antonia (2000). "I diritti animali". En Chieffi, Luciano (a cura di): Bioetica e diritti dell'uomo. Torino: Paravia, pp. 291-302

- Lo Castro, Gaetano (1989). "Legge e coscienza". Quaderni di Diritto e Politica Ecclesiastica, No 2, pp. 15-60.

(1997). Il mistero del Diritto. Torino: Giappichelli.

- Marchei, Nadia (2007). "L'accordo tra la Santa Sede e Slovacchia sull'obiezione di coscienza al vaglio del Parlamento Europeo". Quaderni di Diritto e Politica Ecclesiastica, No 1, pp. 203-218.

- Martí, José María (1999). "La objeción de conciencia: visión de conjunto". Anuario de Derecho Eclesiástico del Estado, vol. XV, pp. 39-62.

- Martín Mateo, Ramón (1987). Bioética y Derecho. Barcelona: Ariel.

- Martín Sánchez, Isidoro (2005). "Bioética y libertad religiosa”. En AA. VV. Bioética, Religión y Derecho. Madrid: Fundación Universitaria Española, pp. 207-256.

(2005). "Bioética y religión". En Martín SÁnchez, Isidoro (coordinador). Bioética, Religión y Salud. Madrid: Comunidad Autónoma de Madrid, pp. 38 y ss.

- Martínez-Pujalte, Antonio Luis (1999). "Libertad de conciencia y tratamiento médico". Persona y Derecho, vol. 41, pp. 379-415.

- Martínez Torrón, Javier (1993). "La giurisprudenza degli organi di Strasburgo sulla libertà religiosa”. Rivista Internazionale dei Diritti dell'Uomo, pp. 344 y ss.

(1997). "La ley española al jurado y la objeción de conciencia de clérigos y religiosos". Ius Canonicum, vol. XXXVII, No 73, pp. 295-310.

(2005). "Las objeciones de conciencia de los católicos". Revista General de Derecho Canónico y Eclesiástico del Estado, vol. 9, pp. 1-35. Disponible en http://www.iustel.com

(1989). "Las objeciones de conciencia en el Derecho internacional". Quaderni di Diritto e Politica Ecclesiastica. No 2, pp. 149-194.

(1992). "Las objeciones de conciencia y los intereses generales del ordenamiento". Revista de la Facultad de Derecho de la Universidad Complutense, vol. 79, pp. 199-217.

- Martínez Torrón, Javier; Navarro Valls, Rafael (2006). "Protecting conscientious objection as a fundamental right. Considerations on the draft agreements of the Slovak Republic with the Catholic Church and with other registered Churches". Revista General de Derecho Canónico y Eclesiástico del Estado, vol. 12, pp. 1-28. Disponible en http://www.iustel.com

- Meyer-Bisch, Patrice (2002). "Le droit à la liberté de conscience dans le champ religieux selon la logique des droits culturels". Revue de Droit Canonique, vol. 52, No 1, pp. 9-25. 
- Motilla, Agustín (1993). "Consideraciones en torno a la objeción de conciencia en el Derecho español". Ius Canonicum, vol. XXXIII, No 65, pp. 141-150.

- Navarro Valls, Rafael (1985). "La enseńanza del Derecho canónico en la jurisprudencia española". Anuario de Derecho Eclesiástico del Estado, vol. I, pp. 49-92.

(2007). "Las objeciones de conciencia". En Ferrer OrTIZ, Javier (coordinador): Derecho eclesiástico del Estado Español. 6a ed. Pamplona: EUNSA, pp. 143-176

(1993). "Los Estados frente a la Iglesia". Anuario de Derecho Eclesiástico del Estado, vol. IX, pp. 17-52.

- Navarro Valls, Rafael; Martínez Torrón, Javier (1997). Las objeciones de conciencia en el Derecho español y comparado. Madrid: McGraw Hill.

- Navarro-Valls, Rafael; Martínez-Torrón, Javier; Jusdado, Miguel Ángel (1988). "La objeción de conciencia a los tratamientos médicos: Derecho comparado y Derecho espańol". Persona y Derecho, vol. 18, pp. 163-277.

- Navarro-Valls, Rafael; Palomino, Rafael (1994). "Las objeciones de conciencia". En AA. VV. Tratado de Derecho eclesiástico. Pamplona: EUNSA, pp. 1089-1198.

- Ollero, Andrés (2006). Bioderecho: entre la vida y la muerte. Pamplona: Aranzadi.

(2001). Democracia y convicciones en una sociedad plural. Pamplona: Navarra Gráfica Ediciones.

- Palazzani, Laura (2002). "Diritto e morale di fronte alla protezione della vita umana". Persona y Derecho, vol. 46, pp. 165-177.

- Palomino, Rafael (2007). "Nuevos supuestos y formas de objeción de conciencia en los Estados Unidos de Norteamérica". Revista General de Derecho Canónico y Eclesiástico del Estado, vol. 15, pp. 1-23. Disponible en http://www.iustel.com

(1994). Las objeciones de conciencia. Madrid: Montecorvo.

- Polaino-Lorente, Aquilino (1994). "Ciencia y conciencia". En él mismo (director). Manual de Bioética general. Madrid: Rialp.

- Prieto Sanchís, Luis (2007). "Desobediencia civil y objeción de conciencia". En AA. VV.: Objeción de conciencia y función pública. Madrid: Consejo General del Poder Judicial. Estudios de Derecho Judicial (89), pp. 11-42.

(2006). "Libertad y objeción de conciencia". Persona y Derecho, vol. 54, pp. 259-273.

- Prisco, Salvatore; Cappuccio, Laura (2000). "Obiezione di coscienza e trattamenti sanitari obligatori". En Chieffi, Luciano (a cura di): Bioetica e diritti dell'uomo. Torino: Paravia. 
- Roca, María J. (2005). "Diversidad cultural y universalidad de los derechos: retos para la fundamentación del Derecho". Anuario Iberoamericano de Justicia Constitucional, vol. 9, pp. 357-377.

- Roca, María J. (2005). "El Derecho canónico como disciplina jurídica básica: implicaciones para su docencia e investigación en las Facultades de Derecho". Revista General de Derecho Canónico y Eclesiástico del Estado, vol. 7, pp. 1-19. Disponible en http://www.iustel. com

- Roca Fernández, María J. (coordinadora) (2007). Opciones de conciencia. Propuestas para una ley. Valencia: Tirant lo Blanch.

- Roca, María J. (2005). “'Teoría’ y 'práctica’ del principio de laicidad del Estado. Acerca de su contenido y su función jurídica". Persona y Derecho, vol. 53, pp. 223-258.

- Romeo Casabona, Carlos María (2004). "El alcance del derecho a la vida en relación con el concebido según el Tribunal Europeo de Derechos Humanos". Revista Derecho y Genoma Humano, vol. 20, pp. 163-173.

- Ruiz Miguel, Alfonso (1996). "La objeción de conciencia, en general y en deberes cívicos". Revista Española de Derecho Constitucional, vol. 47, pp. 101-124.

- Serrano, José Luis (2006). "La clasificación de los derechos constitucionales y el ejercicio abusivo de derechos fundamentales". Persona y Derecho, vol. 54, pp. 275-303.

- Serrano Ruiz-Calderón, José Manuel (2005). Retos jurídicos de la bioética. Madrid: Ediciones Internacionales Universitarias.

(2000). "Sobre el reconocimiento y regulación legal del derecho a la eutanasia". Humana Iura, vol. 10, pp. 111-141.

- Smend, Rudolf (1985) Constitución y Derecho constitucional. Madrid: Centro de Estudios Políticos y Constitucionales.

- Souto Paz, José Antonio (2003). Comunidad política y libertad de creencias, $2^{\text {a }}$ ed. Madrid: Marcial Pons.

- Starck, Christian (1979). El concepto de ley en la Constitución alemana. Madrid: Centro de Estudios Constitucionales.

(2004). "Consenso fundamental nacional y Tribunales constitucionales (una reflexión jurídica comparada”. Anuario Iberoamericano de Justicia Constitucional, vol. 8, pp. 539-556.

(2001). "El estatuto moral del embrión". Revista de Derecho y Genoma Humano, vol. 15, pp. 139-149.

(2005). "Introducción a la dignidad humana en el Derecho alemán". Anuario Iberoamericano de Justicia Constitucional, vol. 9, pp. 489-497.

(2003). "La legitimación de la justicia constitucional y el principio democrático". Anuario Iberoamericano de Justicia Constitucional, vol. 7, pp. 479-493. 
- Tavano, Francesco (2003) I diritti degli animali: nuova legge a tutela degli animali. Milano: FAG.

- Turchi, Vincenzo (2007). "Nuevas formas de objeción de conciencia". Revista General de Derecho Canónico y Eclesiástico del Estado, vol. 15, pp. 1-32. Disponible en http://www.iustel.com

- VÁzquez García-Peñuela, José María (1998). "Constitución, pluralismo y dignidad humana: en torno a las cuestiones fundamentales del Derecho eclesiástico español". Il Diritto Ecclesiastico, No 2, pp. 437-449.

- Vega Gutiérrez, Ana María (1996). "Bioética y Derecho: razón y ética versus razón ética". En Goti Ordeñana, Juan. Secularización y laicidad en la experiencia democrática moderna. San Sebastián: Librería Carmelo, pp. 203-223.

- _ (1996). "El derecho a la vida o el retroceso en la civilización. Crónica del Simposio "Evangelium Vitae e Diritto"”. Ius Canonicum, vol. 72, pp. 715-743.

- Vila-Coro, María Dolores (2003) La bioética en la encrucijada. Madrid: Dykinson. 